\title{
In-Air Vibration Analysis of Three Mile Island Unit-2 Once-Through Steam Generator Tubes Volume 1
}

tordis

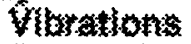

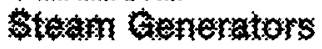




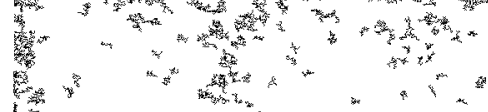

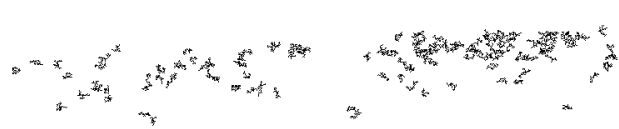

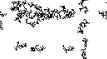
,
, th * tow

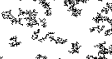

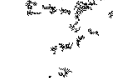

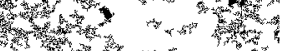

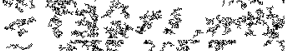




\section{DISCLAIMER}

This report was prepared as an account of work sponsored by an agency of the United States Government. Neither the United States Government nor any agency Thereof, nor any of their employees, makes any warranty, express or implied, or assumes any legal liability or responsibility for the accuracy, completeness, or usefulness of any information, apparatus, product, or process disclosed, or represents that its use would not infringe privately owned rights. Reference herein to any specific commercial product, process, or service by trade name, trademark, manufacturer, or otherwise does not necessarily constitute or imply its endorsement, recommendation, or favoring by the United States Government or any agency thereof. The views and opinions of authors expressed herein do not necessarily state or reflect those of the United States Government or any agency thereof. 


\section{DISCLAIMER}

Portions of this document may be illegible in electronic image products. Images are produced from the best available original document. 


\title{
In-Air Vibration Analysis of Three Mile Island Unit-2 Once-Through Steam-Generator Tubes Volume 1
}

\author{
EPRT NP-2692, Volume 1 \\ Research Project S140-1 \\ Topical Report, October 1982
}

\author{
Prepared by \\ THE BABCOCK \& WILCOX COMPANY \\ Nuclear Power Group \\ Nuclear Power Generation Division \\ P.O. Box 1260 \\ Lynchburg, Virginia 24505 \\ Principal Investigator \\ J. C. Simonis
}

\section{NOTICE}

PORTIONS OF THIS REPORT ARE ILLEGIBLE. It

has been reproduced from the best available

copy to permit the broadest possible avait-

ability.

\section{Prepared for}

Steam Generator Owners Group

and

Electric Power Research Institute

3412 Hillview Avenue

Palo Alto, California 94304

EPRI Project Manager

D. A. Steininger

Nuclear Power Division 


\section{ORDERING INFORMATION}

Requests for copies of this report should be directed to Research Reports Center (RRC), Box 50490, Palo Alto, CA 94303, (415) 965-4081. There is no charge for reports requested by EPRI member utılities and affiliates, contributing nonmembers, U.S. utility associations, U.S government agencies (federal, state, and local), media, and foreign organizations with which EPRI has an information exchange agreement On request, RRC will send a catalog of EPRI reports.

\section{NOTICE}

This report was prepared by the organization(s) named below as an account of work sponsored by the Electric Power Research Inststute, Inc (EPRI) and the Steam Generator Owners Group Nelther EPRI, members of EPRI, the Steam Generator Owners Group, the organization(s) named below, nor any person actıng on behalf of any of them (a) makes any warranty, express or implied, with respect to the use of any information, apparatus, method, or process disclosed in this report or that such use may not infringe privately owned rights, or (b) assumes any liabilities with respect to the use of, or for damages resulting from the use of, any information, apparatus, method, or process disclosed in this report

Prepared by

The Babcock \& Wilcox Company

Lynchburg, Vırgınıa 
EPRI PERSPECTIVE

\section{PROJECT DESCRIPTION}

Circumferential tube cracking has occurred in once-through steam generators (OTSGs). The majority of the tube leaks have occurred in tube rows adjacent to an untubed lane (a tube row without tubes) at either the uppermost tube support plate or upper tubesheet. It has been speculated that a fatigue process induced by tube vibration could be the cause of these leaks. RPS140-1, for which this is a topical report, measures and evaluates the vibration characteristics in the top span of selected steam generator tubes at Three Mile Island Unit-2 (TMI-2). This report discusses the determination of tube resonant frequencies and mode shapes for randomly selected tubes and a limited number of permanently instrumented tubes prior to steam generator operation. These in-air test results are required for interpreting test data acquired from the permanently installed instrumentation during power operation at TMI-2. This effort is documented in the final report of the project.

PROJECT OBJECTIVES

The objectives of the in-air measurement portion of the overall TMI- 2 vibration test program are:

- To determine the range of the first and second frequency cluster of 100 randomly selected tubes

- To determine the mode shape of a limited number of the 23 permanently instrumented tubes

- To evaluate the relationship between the cluster of the first and second resonant frequencies and variations in the boundary conditions of the tubes

\section{PROJECT RESULTS}

This two-volume report summarizes and interprets the in-air test data for the B OTSG at TMI-2. Volume 1 is the main body of the report. Volume 2 contains the appendixes, which include the records of all measurements compiled on microfiche. 
Tubes were identified for frequency content and modal analysis, and a cross-spectral analysis between colinear accelerometer axes in the specific tubes was conducted. This information was used in the interpretation of the measurements taken during power operation, and it is documented in the final report of the project.

This report should be of interest to steam generator designers, individuals evaluating flow-induced vibration and tube response in banks of tubes, and utility personnel responsible for steam generator reliability.

D. A. Steininger, Project Manager Nuclear Power Division 
ABSTRACT

Resonant frequencles were determined for 100 randomly selected tubes and tubes selected for instrumentation during power operation. The average fundamental resonant frequency of the tubes tested was approximately $65 \mathrm{~Hz}$. No spatial distribution of resonant frequency associated with the OTSG was discerned.

Mode shapes were determined for five tube spans bounded by the fifteenth support plate and upper tubesheet and one tube span between the ninth and tenth support plates. The boundary conditions associated with the mode shapes varıed from simple support to clamped at both ends.

The in-air test results are useful for interpreting test data acquired from the permanently installed instrumentation during power operation at Three Mile Island Unit 2 . 


\section{ACKNOWLEDGMENTS}

The author is grateful for the help of the individuals and sections who participated in this test program: J. R. Johnsen, for his assistance during data acquisition and helpful technical discussion during interpretation of the data; the Electronics Service section (Customer services) for the installation and operation of the data acquisition equipment, and the component Engineering section for the special mechanical fixtures needed for the measurements. 
CONTENTS

VOLUME 1

Section Page

1. INTRODUCTION . . . . . . . . . . . . . . . . . . . . . . . 1-1

1.1. Background . . . . . . . . . . . . . . . . . . . . . . 1-1

1.2. Program Objectives . . . . . . . . . . . . . . . . . . 1-1

1.3. In-Air Test Objectives.................. . . . 1-2

1.4. Report Objectives . . . . . . . . . . . . . . . . . . 1-2

2. INSTRUMENTATION AND MEASUREMENTS . . . . . . . . . . . . . . . . . . 2-1

2.1. Introduction . . . . . . . . . . . . . . . . . . . . . 2-1

2.2. Measurement Locations . . . . . . . . . . . . . . . . . 2-1

2.2.1. Random Tube Locations . . . . . . . . . . . . . 2-1

2.2.2. Instrumented Tube Locations . . . . . . . . . . . 2-1

2.3. Data Acquisition Instrumentation . . . . . . . . . . . . . . 2-1

2.4. Data Reduction . . . . . . . . . . . . . . . . . . . 2-2

3. TEST RESULTS . . . . . . . . . . . . . . . . . . . . . 3-1

3.1. Introduction . . . . . . . . . . . . . . . . . . . . . 3-1

3.2. Resonant Frequencies of Randomly Selected Tubes . . . . . . . . . 3-1

3.3. Response Characteristics of Instrumented Tubes . . . . . . . . . . 3-2

3.3.1. Resonant Frequencies . . . . . . . . . . . . . . 3-2

3.3.2. Mode Shape ...................... . . $3-3$

3.4. Preoperational Test Results . . . . . . . . . . . . . . . 3-4

4. DISCUSSION OF RESULTS . . . . . . . . . . . . . . . . . . . . . . 4-1

4.1. Effect of Boundary Conditions . . . . . . . . . . . . . . . . . 4-1

4.2. Influence of Axial Loads . . . . . . . . . . . . . . . . . . . 4-1

4.3. Comparison With Other Test Results................ . . 4-3

5. CONCLUSIONS . . . . . . . . . . . . . . . . . . . . . . . . 5-1

6. RECOMMENDATIONS . . . . . . . . . . . . . . . . . . . . . . 6-1

7. REFERENCES . . . . . . . . . . . . . . . . . . . . . . . 7-1 APPENDIXES

A. TMI-2 In-Air Test Procedure . . . . . . . . . . . . . . A-1

B. Test Case . . . . . . . . . . . . . . . . . . B-1 
CONTENTS (Cont'd)

VOLUME 2

(Available in microfiche only)

\section{APPENDIXES}

C. In-Air Spectral Records . . . . . . . . . . . . . . . $\mathrm{C}-1$

D. Spectral Records for Instrumented Tubes . . . . . . . . . . . D-1

E. Cross-Channel Analysis . . . . . . . . . . . . . . . . . E-1 
ILLUSTRATIONS

Figure $\quad$ Page

2-1. TMI-2 OTSG Instrumentation Pattern . . . . . . . . . . . . . . . 2-6

2-2. Instrumentation Scheme for Resonance Measurements . . . . . . . . . 2-7

2-3. Instrumentation Scheme for Model Evaluation . . . . . . . . . . . . 2-8

3-1. Frequency Distribution of Bandwidth for Random Sample... . . . . 3-7

3-2a. Distribution of Minimum Frequency Range for $W-X$ Quadrant . . . . . 3-8

3-2b. Distribution of Minimum Frequency Range for X-Y Quadrant . . . . . 3-9

3-2c. Distribution of Minimum Frequency Range for $\mathrm{Y}-\mathrm{Z}$ Quadrant . . . . . 3-10

3-2d. Distribution of Minimum Frequency Range for $\mathrm{Z}-\mathrm{W}$ Quadrant . . . . . . 3-11

3-3. Distribution of Minimum Frequency Range for Peripheral Tube

Within 10 Rows of Outside . . . . . . . . . . . . . . . . 3-12

3-4. Weighted Distribution of Minimum Response Frequency . . . . . . . 3-13

3-5. Frequency Distribution of Bandwidth for Instrumented Locations . . . 3-14

3-6. Distribution of Minimum Frequency Range for Instrumented

Locations . . . . . . . . . . . . . . . . . . . . 3-15

3-7. Spectral Response of Tube 77-035 - Fixed Accelerometer . . . . . 3-16

3-8. Spectral Response of Tube 77-035 - Movable Accelerometer . . . . . 3-17

3-9. Spectral Cross Properties of Paired Measurement Locations . . . . . 3-18

3-10a. Mode Shape for Tube 77-035 with Corresponding Resonant

Frequency $52 \mathrm{~Hz}$. . . . . . . . . . . . . . . . . . . . 3-19

3-10b. Orthogonal Mode Shape for Tube 77-035 with Corresponding

Resonant Frequency $53 \mathrm{~Hz}$. . . . . . . . . . . . . . . . 3-20

3-10c. Mode Shape for Tube 77-035 with Corresponding Resonant

Frequency $63 \mathrm{~Hz}$. . . . . . . . . . . . . . . . . . . . . . . . . 3-21

3-10d. Orthogonal Mode Shape for Tube 77-015 with Corresponding

Resonant Frequency $62 \mathrm{~Hz}$. . . . . . . . . . . . . . . . . 3-22

3-10e. Mode Shape for Tube 71-019 with Corresponding Resonant

Frequency $52 \mathrm{~Hz}$. . . . . . . . . . . . . . . . . . . . . . 3-23

3-10f. Orthogonal Mode Shape for Tube 71-019 with Corresponding

Resonant Frequency $52 \mathrm{~Hz}$. . . . . . . . . . . . . . . . 3-24

3-10g. Mode Shape for Tube 39-114 with Corresponding Resonant

Frequency $65 \mathrm{~Hz}$. . . . . . . . . . . . . . . . . . . . 3-25

3-10h. Orthogonal Mode Shape for Tube 39-114 with Corresponding

Resonant Frequency $65 \mathrm{~Hz}$. . . . . . . . . . . . . . . . 3-26

3-10i. Mode Shape for Tube 13-069 with Corresponding Resonant

Frequency $66 \mathrm{~Hz}$. . . . . . . . . . . . . . . . . . . . . . 3-27

3-10j. Orthogonal Mode shape for Tube 13-069 With Corresponding

Resonant Frequency $69 \mathrm{~Hz}$. . . . . . . . . . . . . . . . 3-28

3-10k. Mode Shape for Tube 12-068 (Ninth/Tenth Span) with Corresponding

Rescnant Frequency $53 \mathrm{~Hz}$. . . . . . . . . . . . . . . . . 3-29

3-10l. Orthogonal Mode Shape for Tube 12-068 (Ninth/Tenth Span) With

Corresponding Resonant Frequency $53 \mathrm{~Hz}$. . . . . . . . . . . . . 3-30

3-11. Minimum Frequency Range With Installed Accelerometer . . . . . . . 3-31

4-1. Theoretical Response Spectrum . . . . . . . . . . . . . . . . . 4-4

4-2. Mode Shape Comparison - Analytical and Experimental . . . . . . . 4-5

4-3. Resonance Ratio - Second/First Resonance . . . . . . . . . . . . . 4-6

4-4. Influence of Axial Load on First and Second Resonances . . . . . . 4-7 


\section{.}


TABLES

Table

Page

2-1. Locations of Randomly Distributed Tubes . . . . . . . . . . . . . 2-4

2-2. Modal Test Positions . . . . . . . . . . . . . . . . . 2-5

2-3. Ninth/Tenth Span Excitation . . . . . . . . . . . . . . . . 2-5

3-1. Average Resonant Spectral Peaks . . . . . . . . . . . . . . . . 3-5

3-2. Mode Shape Coefficients . . . . . . . . . . . . . . . . . . 3-6

4-1. Resonant Frequencies of OTSG Tubes Previously Reported, Hz . . . . . 4-3 

EXECUTIVE SUMMARY

This report documents and interprets accelerometer test data taken in air for the $B$ once-through steam generator at Three Mile Island 2. The objectives for this test were as follows:

1. determine the range of the first and second frequency cluster of 100 randomly selected tubes,

2. determine the mode shape of a limited number of the 23 instrumented tubes, and

3. evaluate the relationship between the cluster of the first and second resonant frequencies and variations in the boundary conditions of the tubes including axial preload.

To accomplish the above objectives tubes were identified for modal analysis, and a cross-spectral analysis between colinear accelerometer axes in the specific tubes was conducted. These data were used to estimate the mode shapes using a curve fit.

\section{Results}

Resonant frequencies for the 100 randomly selected tubes and the 23 instrumented tubes were evaluated. The mode shape was determined for six tube spans: two tube spans whose resonant frequency was lower than the mean, one whose resonant frequency was near the mean, two whose frequency was greater than the mean, and a tube span between the ninth and tenth support plate.

A calculated theoretical stress spectrum using a finite element model of a fulllength OTSG tube built in at the upper and lower tubesheets and simply supported at the intermediate support plates compared favorably with the measured spectra. 
It was difficult to establish, with an acceptable confidence level, from the test results a value of the axial preload that one could expect for the tubes of the OTSG. The results suggest that the magnitude of the tensile or compressive forces imposed on a tube by manufacturing depend on the mode considered. This circumstance is attributed to the lack of true classical boundary conditions at the support plates.

In comparing the results of this test and those conducted at other oTSGs, consistent results were not obtained. The ranges of natural frequencies determined for Oconee Unit 1 and Davis-Besse Unit 1 are lower than the resonant response frequencies in air obtained for the Oconee 2 OTSG B. Furthermore, the results from Oconee 2 are comparable to those obtained at TMI-2 for the B OTSG. For both the Oconee 2 and TMI-2 tests, the resonant frequency results are higher than those obtained from Oconee 1, OTSG A, and Davis-Besse 1 .

\section{Conclusions}

Interpretation of the results from the in-air tests conducted on OTSG B at TMI-2 led to the following conclusions:

1. The spectrum obtained from the in-air measurements on an individual span agrees in form with those obtained from an analytical model. Both spectra contain multiple frequencies attributed to near- and far-field coupling between spans.

2. The resonant response of a tube span depends on the boundary conditions. The actual boundary conditions existing in a steam generator are not classical but vary between built-in at both ends or built-in and simply supported with varying axial loads.

3. Variations in the boundary conditions for an actual tube in a steam generator preclude using resonant frequency measurements alone as a method of determining the amount of axial load existing in a tube. This method may be used in conjunction with other measurements which can determine boundary conditions.

4. The boundary conditions determined for a tube span from the in-air tests are believed to be influenced by the level of the excitation force. The acoustic excitation of the tubes was small and may not have been sufficient 
to overcome the moment restraint imposed on the tube span at the support plate. The support plate moments were induced by frictional forces between the tube and the support plate, misalignment between the tube and the holes in the support plate, and imperfections in the tube.

5. The resonant frequencies measures in the in-air tests at TMI-2 and Oconee 2 are similar. However, they are higher than those obtained from previously reported in-air measurements at oconee 1 or Davis-Besse. 

Section 1

INTRODUCTION

\subsection{Background}

Tests had been performed before 1974 to determine the vibration characteristics of several tubes in the once-through steam generator (OTSG). These tests provided fundamental frequency data that agreed with calculations based on axial load elastic beam theory. Further, the results provided data indicating that the initial tube preload was in reasonable agreement with tube preloads expected to result from manufacturing.

The results of the tests and additional eddy-current results from operating OTSGs suggested the merit of an extensive program to measure the vibratory response of a large number of tubes in a single steam generator under a variety of operating conditions. The operating conditions included normal plant transients and abnormal operating transients purposely induced during plant startup. Therefore, a single comprehensive test was conducted for the B OTSG in Three Mile Island Unit 2 (TMI-2).

The selection of the 23 tubes to be instrumented in TMI-2 was based on the pattern of tube leaks observed from other OTSGs and tube anomalies identified by eddy-current examinations in operating steam generators. Observation and examination identified the majority of the tube leaks as occurring in tubes adjacent to the untubed lane near the fifteenth support plate or the upper tubesheet. Metallurgical inspection of several of the failed tubes revealed circumferential cracks through the tube wall. Additional metallurgical analyses of tubes that have failed showed that the crack propagation may have been the result of high cycle fatigue.

\subsection{Program Objectives}

The measurement program conducted on the TMI-2 B OTSG was performed to provide tube response data, flow data, and plant process data during transient and steady-state operation. ${ }^{1}$ These data are to be used to evaluate the effects of the normal and transient plant operating conditions on tubes. Program objectives were defined that deal with the evaluation of tube response during steady-state and transient 
operating conditions. To fulfill these objectives, a secondary in-air test program was defined.

The in-air portion of the overall TMI-2 test program was performed to provide the vibratory characteristics of the instrumented tube spans and other randomly selected spans. These data aid in interpreting the response data acquired during normal and transient plant operating conditions.

\subsection{In-Air Test Objectives}

To accomplish the purposes of the in-air portion of the overall TMI-2 test program, three objectives were defined:

1. To determine the range of the first and second frequency cluster of 100 randomly selected tubes.

2. To determine the mode shape of a limited number of the 23 instrumented tubes.

3. To evaluate the relationship between the cluster of the first and second resonant frequencies and variations in the boundary conditions of the tubes.

\section{4. Report Objectives}

This report summarizes and interprets the in-air test data for the B OTSG at TMI-2. Tubes were identified for modal analysis, and a cross-spectral analysis between colinear accelerometer axes in the specific tubes was conducted. These data were used to estimate the mode shapes using a quartic polynomial curve fit.

Impact tests were performed after installation of the internal and external instrumentation. The data from these tests were used to establish baseline energy transport times for identifying and locating unusual noises in the OTSG. At the time the data were acquired, reduction was not planned unless unusual noises were identified. No unusual noises were detected during the OTSG test program to justify data reduction. The data are preserved on magnetic tape and in the tape library at the Lynchburg Research center. 
Section 2

INSTRUMENTATION AND MEASUREMENTS

\subsection{Introduction}

The TMI-2 in-air test producedure identifies the locations of 23 instrumented tubes and 100 randomly selected tubes selected for this test. Appendix $A$ contains the procedures used to conduct the in-air program on the B OTSG at TMI-2.

\subsection{Measurement Locations}

\subsubsection{Random Tube Locations}

Table 2-1 identifies the locations of the 100 randomly selected tubes evaluated in the in-air portion of the TMI-2 test program for resonant frequency characteristics. The distribution of the 100 randomly selected tubes is nearly equal for each quadrant. Selection of the tubes was based on a Gaussian distribution of random integers. The first integer was used to specify the tube row, and the second was used to specify the tube in the previously selected column.

\subsubsection{Instrumented Tube Locations}

Figure 2-1 shows the locations of the 23 tubes selected for instrumentation in the B OTSG at TMI-2. The tubes selected were parallel to the open lane, normal to the open lane, and on rays 30 and $60^{\circ}$ from the $w$ axis.

The locations were based on failure locations observed along the lane in the OTSG, eddy-current indications from other steam generators, and the uniqueness of the tube patterns in the 30 and $60^{\circ}$ rays. The 30 and $60^{\circ}$ rays represent maximum and minimum flow patterns for the remaining tube bundle. The tubes selected utilized information that had been gained from tests and inspections of all B\&W OTSGs that were in service at the time this test program was formulated.

\subsection{Data Acquisition Instrumentation}

Figure 2-2 shows the instrumentation and data reduction system used for testing the 100 randomly selected tubes. A single biaxial accelerometer (Columbia Model HEVPl4) was inserted into the tube. It was held in position by leaf-type spring feet at an 
axial location $12.5 \pm 0.25$ inches below the lower surface of the tubesheet. The tube was excited by white noise from a speaker mounted in the inspection manway.

The response of the tube to the white noise was preamplified in the containment building and further amplified at the data acquisition trailer. The second amplification provided for gain normalization of the signal. After conditioning, the signal was recorded on a 14-channel standard FM tape recorder. Also, in parallel, the signals were reduced using a spectrum analyzer. These results were plotted and are the data used for the frequency analyses in sections 3 and 4 .

At intervals during the in-air test program, spectrum analyses of tape recorded and real-time data were compared. The spectral results showed agreement in amplitude and spectral content.

Figure 2-3 shows the instrumentation and data reduction system used to acquire the data for modal evaluation of any of the 23 instrumented tubes. Two accelerometers were installed in each tube. The lower accelerometer was classified as the reference device and remained fixed throughout the tests on an individual tube span. The upper accelerometer was movable; it was located as prescribed in Tables 2-2 and 2-3. As in the case for frequency analysis of the randomly selected tubes, the excitation was acoustic white noise.

Signals from both accelerometers were simultaneously preamplified in the containment, gain-normalized, and recorded on a 14-channel tape recorder in the data acquisition trailer. Signals in parallel with the data recording from instrumentation were evaluated using a spectrum analyzer. The spectrum analyses of real-time and recorded data were periodically compared. The spectral analyses agreed in magnitude and spectral form.

\subsection{Data Reduction}

Reduction of the in-air test data was primarily conducted at TMI-2 in real time. The data were reduced using a (Spectral Dynamics SD330) spectrum analyzer.

The data reduction process was divided into two categories. The first was used to judge the acceptability of the recorded data; acceptance was based on the signal: noise ratio and the level of the electrical noise. The second category reduced the data to identify significant spectral peaks in the bandwidth from 0 to $200 \mathrm{~Hz}$. These results on the 23 instrumented spans provided the basis for selecting tubes for modal analysis. 
The modal analysis was based on the coherence, transfer functions, and the phase angles between parallel accelerometer axes. ${ }^{2}$ Coherence values of parallel accelerometer axes approaching unity indicate that the motions detected by the accelerometer axes are related to the same excitation source. The value of the transfer function was recorded.

The phase angle provided further corroboration that coherence values near one were associated with a pure mode. Based on the installation of the accelerometer, the expected phase angle for a pure mode must be either 0 or $180^{\circ}$. The value of the transfer function corresponding to both coherence values of near one and a phase angle of either 0 or $180^{\circ}$ for each measurement location were fit, in a least-square sense, to a fourth-order polynomial. A fourth-order polynomial was selected, rather than the complex modal shape function associated with the vibration of tubes, because of its ability to provide accurate frequency results using energy techniques.

Appendix B contains a test case derived using this technique. The fourth-order polynomial predicts the exact mode shape of a simply supported beam. The confidence level is greater than $99.99 \%$. 
Table 2-1. Locations of Randomly Distributed Tubes

\begin{tabular}{|c|c|c|c|c|c|}
\hline Number & Row & Tube & Number & Row & Tube \\
\hline 1 & 20 & 55 & 51 & 148 & 1 \\
\hline 2 & 105 & 90 & 52 & 71 & 81 \\
\hline 3 & 69 & 23 & 53 & 94 & 102 \\
\hline 4 & 132 & 25 & 54 & 42 & 114 \\
\hline 5 & 107 & 83 & 55 & 24 & 22 \\
\hline 6 & 128 & 93 & 56 & 51 & 116 \\
\hline 7 & 87 & 55 & 57 & 117 & 8 \\
\hline 8 & 75 & 54 & 58 & 48 & 44 \\
\hline 9 & 121 & 28 & 59 & 73 & 61 \\
\hline 10 & 52 & 30 & 60 & 61 & 102 \\
\hline 11 & 33 & 18 & 61 & 114 & 12 \\
\hline 12 & 119 & 35 & 62 & 123 & 77 \\
\hline 13 & 100 & 70 & 63 & 124 & 55 \\
\hline 14 & 44 & 14 & 64 & 87 & 1 \\
\hline 15 & 143 & 20 & 65 & 45 & 52 \\
\hline 16 & 79 & 70 & 66 & 46 & 83 \\
\hline 17 & 132 & 83 & 67 & 42 & 3 \\
\hline 18 & 111 & 3 & 68 & 70 & 112 \\
\hline 19 & 93 & 52 & 69 & 151 & 16 \\
\hline 20 & 29 & 52 & 70 & 63 & 55 \\
\hline 21 & 65 & 70 & 71 & 93 & 83 \\
\hline 22 & 55 & 81 & 72 & 71 & 116 \\
\hline 23 & 135 & 79 & 73 & 64 & 17 \\
\hline 24 & 18 & 39 & 74 & 100 & 18 \\
\hline 25 & 72 & 125 & 75 & 133 & $6 I$ \\
\hline 26 & 17 & 39 & 76 & 116 & 35 \\
\hline 27 & 119 & 3 & 77 & 69 & 106 \\
\hline 28 & 21 & 20 & 78 & 100 & 84 \\
\hline 29 & 31 & 44 & 79 & 30 & 94 \\
\hline 30 & 39 & 79 & 80 & 10 & 45 \\
\hline 31 & 87 & 37 & 81 & 51 & 87 \\
\hline 32 & 151 & 9 & 82 & 96 & 126 \\
\hline 33 & 40 & 100 & 83 & 1 & 11 \\
\hline 34 & 55 & 43 & 84 & 58 & 30 \\
\hline 35 & 82 & 108 & 85 & 114 & 29 \\
\hline 36 & 49 & 93 & 86 & 100 & 63 \\
\hline 37 & 2 & 20 & 87 & 101 & 4 \\
\hline 38 & 83 & 20 & 88 & 17 & 17 \\
\hline 39 & 42 & 55 & 89 & 89 & 57 \\
\hline 40 & 12 & 9 & 90 & 14 & 43 \\
\hline 41 & 39 & 5 & 91 & 48 & 75 \\
\hline 42 & 107 & 103 & 92 & 74 & 50 \\
\hline 43 & 6 & 49 & 93 & 96 & 78 \\
\hline 44 & 150 & 6 & 94 & 70 & 66 \\
\hline 45 & 135 & 54 & 95 & 91 & 97 \\
\hline 46 & 117 & 83 & 96 & 106 & 38 \\
\hline 47 & 82 & 53 & 97 & 85 & 64 \\
\hline 48 & 147 & 30 & 98 & 76 & 108 \\
\hline 49 & 21 & $6 I$ & 99 & 71 & 67 \\
\hline 50 & 57 & 79 & 100 & 134 & 68 \\
\hline
\end{tabular}


Table 2-2. Modal Test Positions

\begin{tabular}{lcc} 
Test & $\begin{array}{c}\text { Location of reference } \\
\text { accelerometer, in. }\end{array}$ & $\begin{array}{c}\text { Location of movable } \\
\text { accelerometer, in. }\end{array}$ \\
\cline { 2 - 3 } 1 & 40.5 & 35 \\
2 & $\downarrow$ & 28.5 \\
3 & $\downarrow$ & 23.5 \\
4 & $\downarrow$ & 17.25 \\
5 & 40.5 & 12 \\
6 & & 6 \\
7 & & In tubesheet
\end{tabular}

Notes: 1. All dimensions are referenced to the bottom surfaces of the upper tubesheet.

2. Tolerance on locations is \pm 0.25 inch.

Table 2-3. Ninth/Tenth Span Excitation

\begin{tabular}{lcc} 
Test & $\begin{array}{c}\text { Location of reference } \\
\text { accelerometer, in. }\end{array}$ & \multicolumn{2}{c}{$\begin{array}{l}\text { Location of movable } \\
\text { accelerometer, in. (a) }\end{array}$} \\
\cline { 2 - 3 } 1 & 257.5 & 218.25 \\
2 & $\mid$ & 227.5 \\
3 & & 233.25 \\
4 & & 238.25 \\
5 & & 242.5 \\
6 & 257.5 & 247.5 \\
7 & & 252.5
\end{tabular}

(a) Measured from lower surface of upper tubesheet. Tolerance on locations is \pm 0.5 inch. 


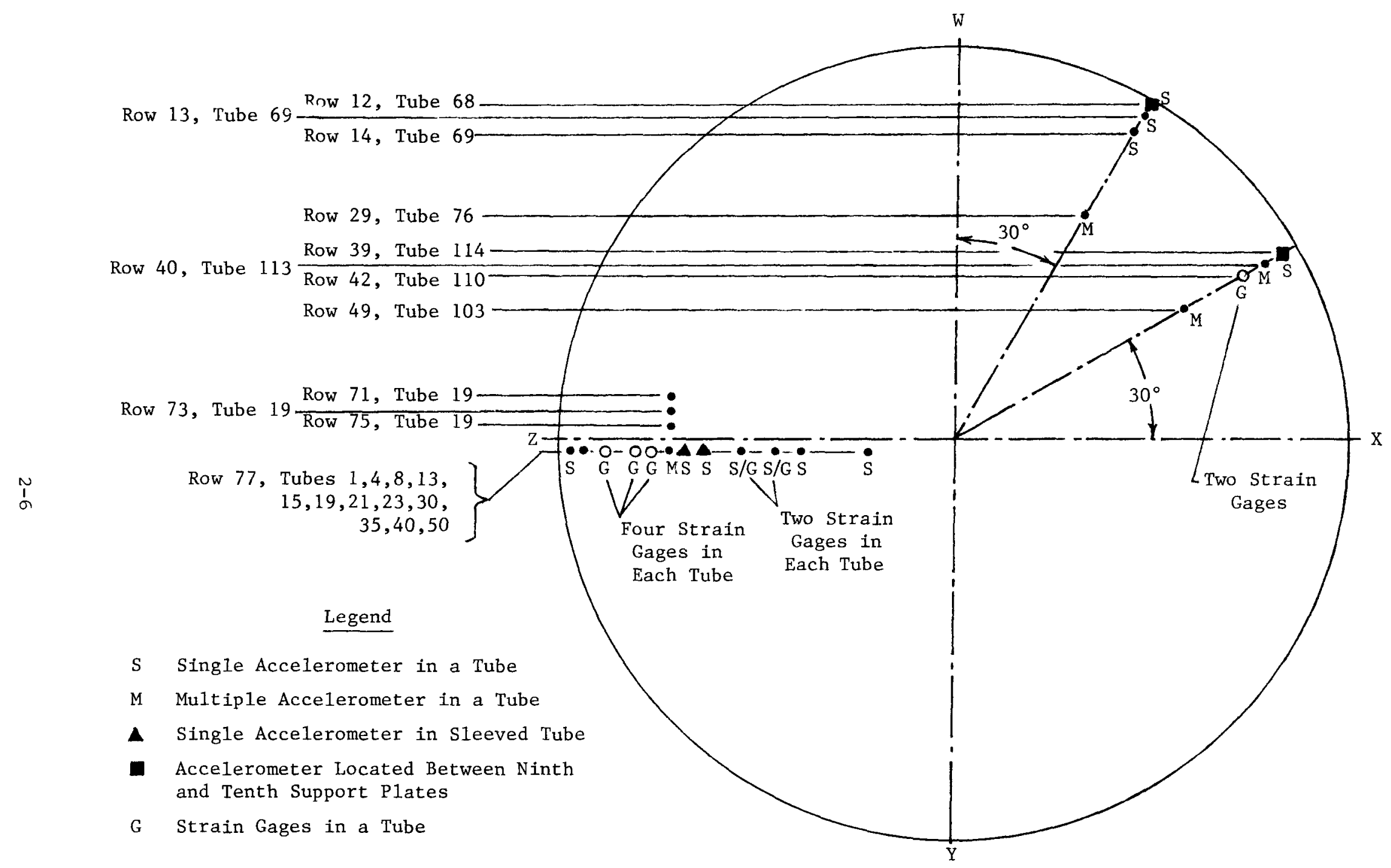

Figure 2-1. TMI-2 OTSG Instrumentation Pattern 


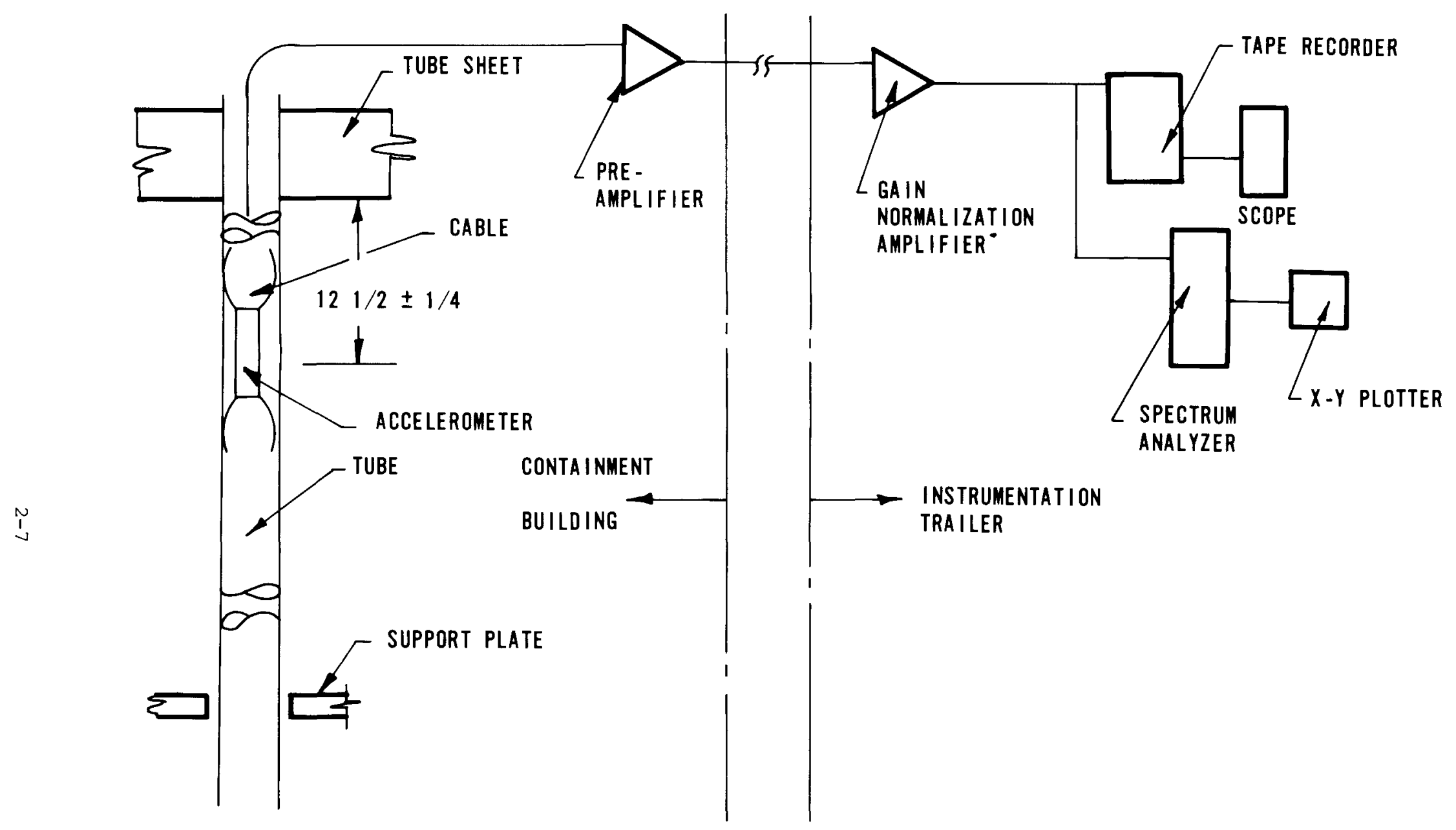

Figure 2-2. Instrumentation Scheme for Resonance Measurements 


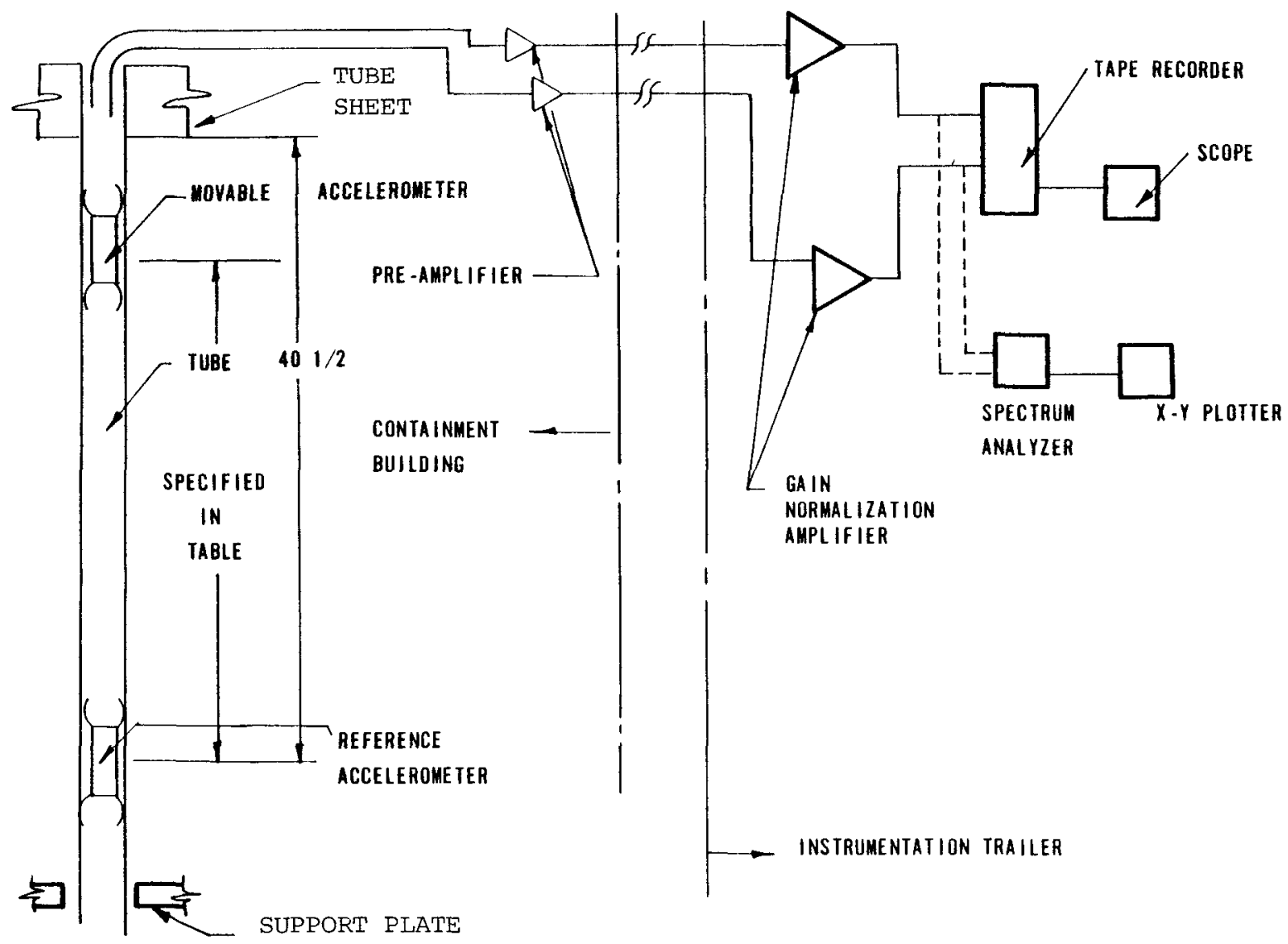

Figure 2-3. Instrumentation Scheme for Model Evaluation 
Section 3

TEST RESULTS

\subsection{Introduction}

Resonant fxequencies for the 100 randomly selected tubes and the 23 instrumented tubes were evaluated. The mode shape was determined for six tube spans: two tube spans whose resonant frequency was lower than the mean, one whose resonant frequency was near the mean, two whose resonant frequency was near the mean, two whose frequency was greater than the mean, and a tube span between the ninth and tenth support plates.

\subsection{Resonant Frequencies of Randomly Selected Tubes}

Table 3-1 lists the average value of resonant spectral peaks for the 100 randomly selected tubes. Representative spectral records are shown in Figure 3-7. Appendix $C$ contains the spectral records for each channel. The average value of the first resonant peak for the tube spans that showed identifiable spectral peaks was $64 \mathrm{~Hz}$, with an associated standard deviation of $3.8 \mathrm{~Hz}$. The average value of the second resonant peak for the tube spans that showed identifiable spectral peaks was $169 \mathrm{~Hz}$, with an associated standard deviation of $6.6 \mathrm{~Hz}$. Not all tube spans tested displayed identifiable resonances corresponding to the first and second resonant frequencies.

Near the resonant frequency value for a single span, a cluster of frequencies bounds this value. These frequencies are a result of multiple spans and a corresponding frequency for each span. Therefore, the resonant frequency for a multiple-supported tube is distributed over a frequency bandwidth.

Figure 3-1 shows the distribution of the frequency range for the randomiy selected tubes as a function of quadrant location. The distribution of the average frequency range and the associated standard deviations for each quadrant overlap. This indicates, to the author, that the fundamental frequency range is independent of the quadrant location of the tube span. 
Figure 3-1 also compares the average fundamental frequency range for the tube spans on the periphery. For a depth of 20 tubes, the average fundamental frequency ranges of the peripheral tube spans are statistically similar to the interior tube spans. Figures 3-2a through 3-2d show the distribution of the fundamental frequency range for each quadrant. These results show that there are extensive bandwidths over which the fundamental resonant frequency of a given tube span occurs. As summarized in Figure 3-1, there is no distinct difference between any particular quadrants when the results are evaluated using the bandwidth of the minimum frequency range.

Figure 3-3 summarizes the results for the individual tubes evaluated on the periphery of the tube bundle. This figure shows that five tube spans, grouped closely together, apparently display lower frequencies. This may result from the small sample or variations in tube axial load.

The response frequency for a tube span with node points defined at the tubesheet or support plate should be bounded between the ideal simply supported and completely fixed boundary conditions. For the tube span bounded by the support plate and tubesheet, the response frequency should be bounded by the ideal simple/fixed support.

Figure 3-4 shows the cumulative distribution weighted by the number of spectral peaks observed at the second resonant frequency cluster. This figure shows the data fitted to a Weibel distribution.

\subsection{Response Characteristics of Instrumented Tubes}

\subsubsection{Resonant Frequencies}

Table 3-1 lists the average values of resonant spectral peaks for the instrumented tubes; Appendix D contains the spectral records. The average value of the first resonant peak for the tube spans that showed identifiable spectral peaks was $65 \mathrm{~Hz}$, with an associated standard deviation of $5.5 \mathrm{~Hz}$. The average value of the second resonant peak for the tube spans that showed identifiable spectral peaks was $171 \mathrm{~Hz}$ with an associated standard deviation of $7.9 \mathrm{~Hz}$.

Comparison of the average resonant values from tests on the tube spans and the selected instrumented tube spans reveals no distinctive statistical difference. The average values are similar and overlap when the standard deviation is considered.

Figure 3-5 shows the distribution of the average value for the fundamental frequency range of the instrumented tube span locations. The frequency value used for these 
plots is the predominant peak that best represents the frequency associated with the top span. These average results suggest a distinct difference between the properties of the tubes located $30^{\circ}$ clockwise from the $\mathrm{W}$-axis and the other tested spans. The tubes $30^{\circ}$ clockwise from the $\mathrm{W}$-axis have a higher average resonant frequency value than the others. However, there are insufficient data to draw an unqualified conclusion.

Figure 3-6 shows the distribution of the fundamental frequency range for the instrumented tube spans. The tubes along the $\mathrm{W}$-axis appear to have a higher fundamental frequency range than the others in the sample.

\subsubsection{Mode Shape}

Figures 3-7 and 3-8 show a typical acceleration spectrum of the upper tube span of a tube for the frequency range from 10 to $75 \mathrm{~Hz}$. (Tube 77-035 was selected as a typical example.) Each spectrum corresponds to a different axial position of the movable accelerometex in the upper tube span. Excitation was provided by acoustically coupled white noise. These response spectra, typical for all instrumented spans tested, show $60 \mathrm{~Hz}$ electrical noise, a half-harmonic of this noise at $30 \mathrm{~Hz}$, and the fundamental resonant frequency range of the tube span. As expected, the resonant frequency range of the tube span shifts slightly as the axial location of the movable accelerometer changes.

Once again these response spectra show clearly that the resonant frequency of a tube span is not single-valued. The resonance in a span is multiple-valued and influenced by adjacent spans.

Figure 3-8 shows that the spectrum changes in amplitude as a function of location and shows a slight shift in the value of the resonant frequency as a function of the location of the movable accelerometer. The change in amplitude is caused by variations in the level of the acoustic excitation. Use of these data requires normalization of the output response by the input response or transfer function. From this analysis, the transfer function phase and coherence between the movable and reference accelerometers are determined.

Figure 3-9 shows the coherence, phase angle, and transfer function between the reference and movable accelerometers in the upper tube span of tube 77-035 for each pair of measurement locations. Appendix E contains the cross-channel analysis of the tube spans evaluated. The reference accelerometer was located 40.5 inches below 
the lower face of the tubesheet, and the movable accelerometer was placed as specified in Tables 2-2 and 2-3. Figure 3-9 shows that near $52 \mathrm{~Hz}$, the coherence between the movable and reference accelerometers exceeds 0.95 except for the test location in the tubesheet. This coherence value quantitatively defines that the motion of both accelerameter axes is produced by the same source. Figure 3-9 also shows that the phase angle between the parallel axis of the reference and movable accelerometers for each test $10 c a t i o n$ is $180^{\circ}$; however, the two accelerometers are in phase. This is due to the fact that the accelerometers are installed from different ends of the steam generator and are therefore mounted $180^{\circ}$ out of phase.

Figure 3-9 shows the transfer function between the parallel axes of the reference and movable accelerometers for each measurement location. The values of the transfer function at each measurement location are the response of the tube normalized for changes in the input excitation level. The transfer functions for high coherence values and proper phase angles were used as input to a fourth-order, curve-fit program to determine the mode shape for a particular tube span in a least-square sense.

Table 3-2 lists the mode shape coefficients for the five upper tube spans and the one between the ninth/tenth span. In addition, this table shows the statistics of the curve fit. For each tube span, two sets of curve-fit coefficients are 1isted; they correspond to mutually orthogonal mode shapes. Figures 3-10a through 3-10l show the mode shapes for five upper span tubes and for the ninth/tenth tube span; these curves show the experimental data used for the curve fit. The curves show that the boundary conditions vary from a condition with no slope at either boundary to the slope at the boundary corresponding to the support plate. Figures 3-10k and 3-10l, the mode shapes for tube 12-068 between the ninth and tenth spans appear to be distorted. However, both figures indicate the expected result for the interior tubes, i.e., a simply supported boundary condition for tubes bounded by support plates. The distortion is attributed to inaccuracies within the data. The excitation level at this location was small and further attenuated by the internal structure within the OTSG.

\subsection{Preoperational Test Results}

Figure 3-11 shows the fundamental frequency range of the tube spans after installation of the instrumentation identified in Appendix A. The fundamental frequency range is approximately 50 to $75 \mathrm{~Hz}$. This range is slightly lower than the fundamental frequency range with the accelerometers used in the in-air tests. Thus, the permanently installed instrumentation slightly reduced the resonant response 
frequencies of the instrumented tubes. The mass associated with the permanently installed accelerometers is greater than that used for the in-air frequency measurements. This lowering of frequency will not affect the results in the power operation tests performed at TMI-2.

Table 3-1. Average Resonant Spectral Peaks

\begin{tabular}{lcc} 
& $\begin{array}{c}\text { Frequency, } \\
\text { Hz }\end{array}$ & $\begin{array}{c}\text { Std deviation, } \\
\mathrm{Hz}\end{array}$ \\
\cline { 2 - 3 } Randomly selected tubes & & 3.8 \\
First peak & 64 & 6.6 \\
Second peak & 169 & \\
Instrumented tubes & & 5.5 \\
First peak & 65 & 7.9 \\
Second peak & 171 &
\end{tabular}


Table 3-2. Mode Shape Coefficients

\begin{tabular}{|c|c|c|c|c|c|c|c|c|}
\hline \multirow{2}{*}{\multicolumn{2}{|c|}{$\begin{array}{l}\text { Tube } \\
\text { ident }\end{array}$}} & & \multicolumn{2}{|c|}{ Statistics } \\
\hline & & $x^{0}$ & $x^{1}$ & $\frac{\text { Coefficien }}{\mathrm{x}^{2}}$ & $x^{3}$ & $x^{4}$ & $\mathrm{RMS}^{(\mathrm{a})}$ & $\begin{array}{l}\text { Coeff of } \\
\text { determin'n }\end{array}$ \\
\hline & $77-035$ & -0.0092 & -5.7261 & 55.4084 & -90.8708 & 41.2715 & 0.211 & 0.966 \\
\hline & $77-035$ & 0.3960 & -12.8152 & 250.1531 & -464.8077 & 226.6877 & 6.139 & 0.970 \\
\hline & $77-015$ & 0.0324 & -3.3635 & 20.7475 & -20.6893 & 3.2573 & 0.056 & 0.978 \\
\hline & $77-015$ & 0.3884 & -3.4122 & 208.0471 & -668.6941 & 364.2524 & 11.152 & 0.951 \\
\hline & $71-019$ & 0.2855 & -42.5300 & 442.5939 & -816.8291 & 417.0275 & 59.184 & 0.779 \\
\hline & $71-019$ & 0.2483 & 16.9641 & -36.0173 & 33.3263 & -14.5837 & 0.6445 & 0.927 \\
\hline & $39-114$ & 0.0484 & 3.8739 & -5.9793 & 18.3456 & -16.4019 & 1.497 & 0.793 \\
\hline & $39-114$ & -0.0317 & 8.2484 & -14.1243 & 11.4772 & -5.5109 & 0.2063 & 0.924 \\
\hline & $13-069$ & -0.0947 & 5.7230 & 41.8581 & -102.9207 & 55.5585 & 0.622 & 0.967 \\
\hline \multirow[t]{3}{*}{$\begin{array}{l}\omega \\
\vdots \\
\alpha\end{array}$} & $13-069$ & 0.0927 & -4.5219 & 289.8606 & -580.5081 & 294.8039 & 3.281 & 0.990 \\
\hline & $12-068$ & 0.6982 & 9.5540 & -34.9229 & 45.6584 & -20.9711 & 0.236 & 0.776 \\
\hline & $12-068$ & 0.8536 & 2.9431 & -6.9502 & 9.5416 & -6.3987 & 0.089 & 0.849 \\
\hline
\end{tabular}

(a) RMS: residual mean square. 


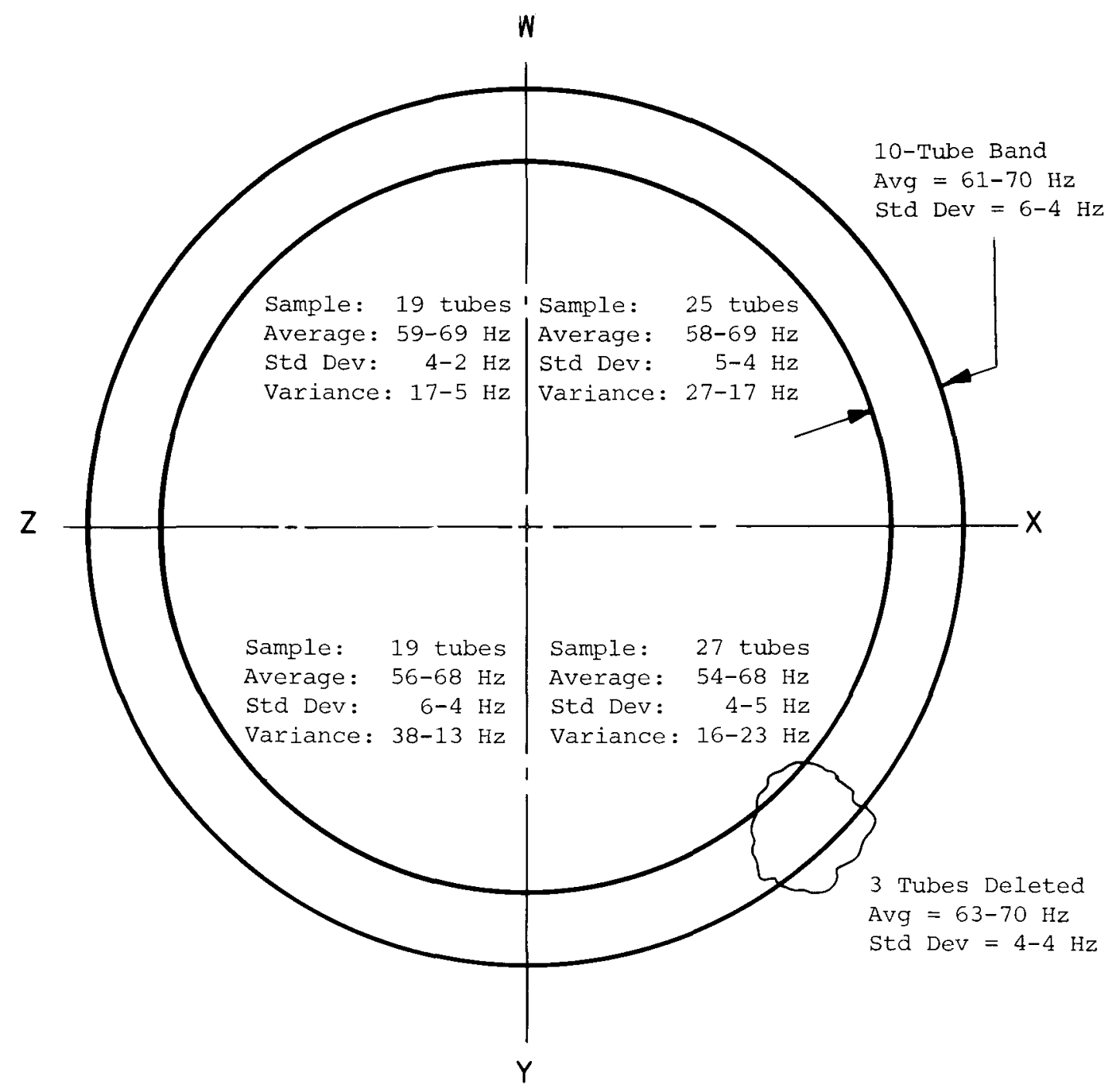

Figure 3-1. Frequency Distribution of Bandwidth for Random Sample 


\section{TUBE IDENTIFICATION}

$20-55$

$119-35$

$44-14$

$65-70$

$55-81$

$72-125$

$40-100$

$49-93$

$21-61$

$57-79$

$71-81$

$42-114$

$51-116$

$61-102$

$46-83$

$70-112$

$71-116$

$69-106$

$51-87$

$1-11$

$14-43$

$48-75$

$70-66$

$76-108$

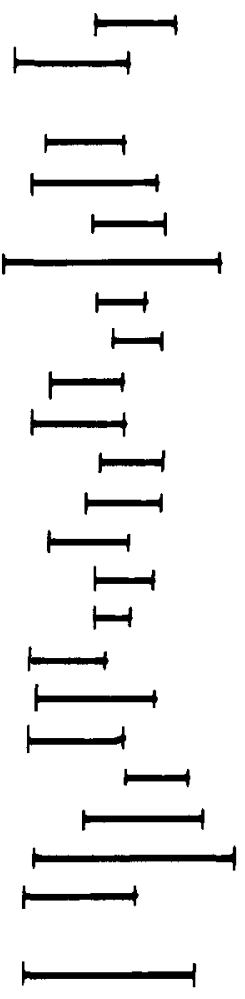

$71-67$

\begin{tabular}{cccccc}
1 & 1 & 1 & 1 & 1 & 1 \\
\hline 0 & 25 & 50 & 75 & 100 & 125 \\
& & Frequency, $\mathrm{Hz}$ &
\end{tabular}

Figure 3-2a. Distribution of Minimum Frequency

Range for $\mathrm{W}-\mathrm{X}$ Quadrant 


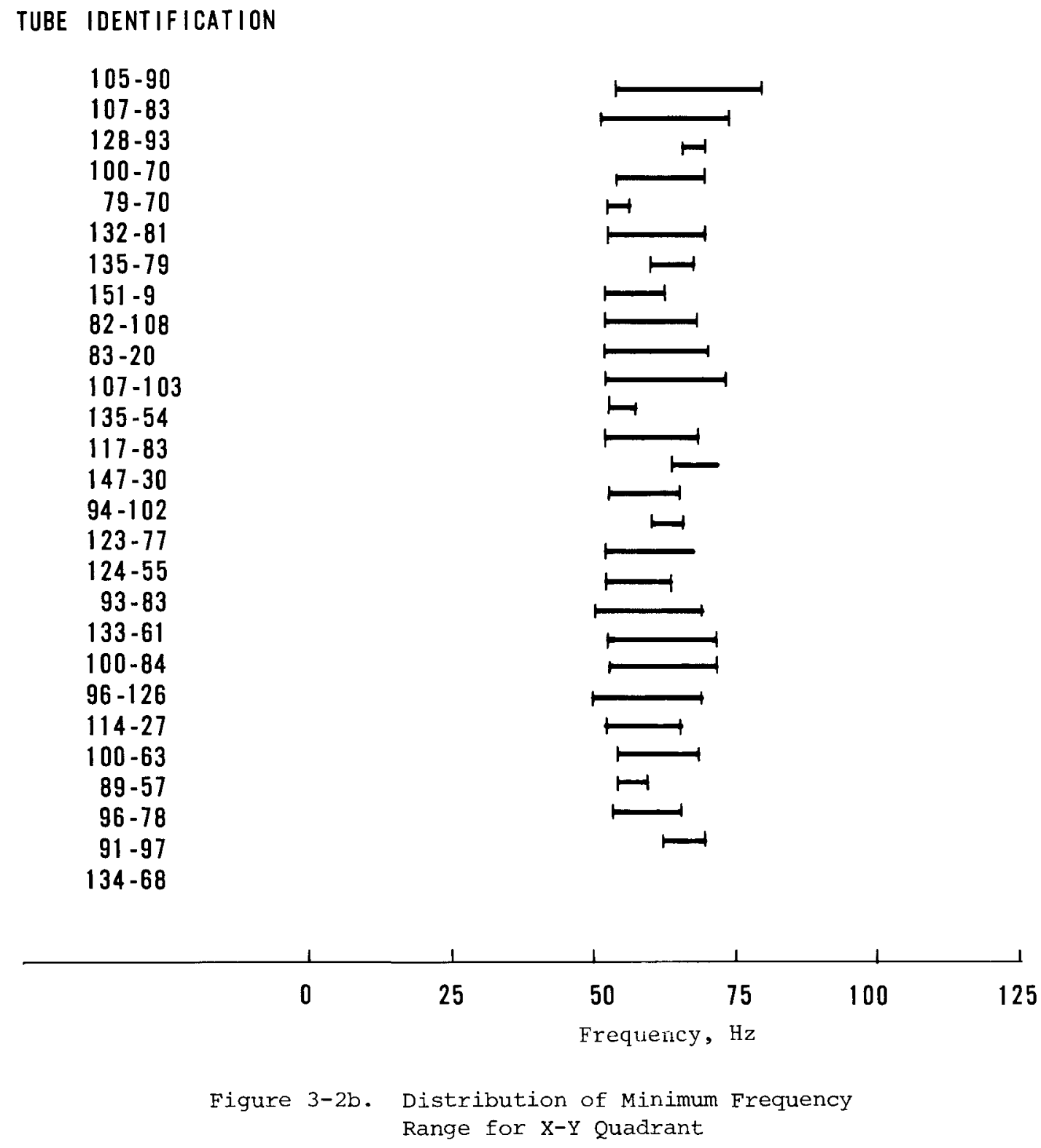




\section{TUBE IDENTIFICATION}
$87-55$
$121-28$
$143-20$
$111-3$
$93-52$
$119-03$
$87-37$
$150-06$
$82-53$
$148-01$
$117-08$
$114-12$
$87-01$
$151-16$
$100-18$
$116-35$
$101-04$
$106-38$
$85-64$

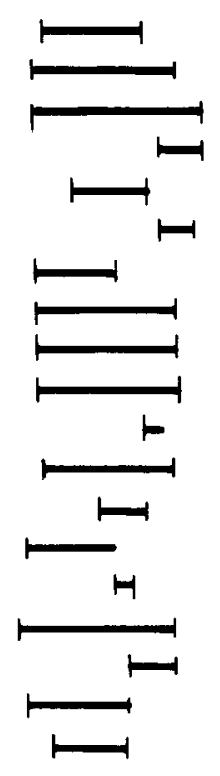

\begin{tabular}{cccccc}
\hline & 1 & 1 & 1 & 125 \\
0 & 25 & 50 & 75 & 100 & 125 \\
& & Frequency, $\mathrm{Hz}$ & &
\end{tabular}

Figure 3-2c. Distribution of Minimum Frequency Range for $\mathrm{Y}-\mathrm{Z}$ Quadrant 
TUBE IDENTIFICATION
$69-23$
$135-25$
$75-54$
$52-30$
$18-39$
$17-39$
$21-20$
$55-43$
$42-55$
$12-09$
$24-22$
$48-44$
$73-61$
45-52
$42-03$
$63-55$
$64-17$
$58-30$
$74-50$

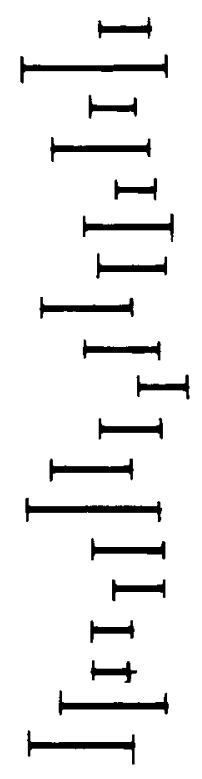

\begin{tabular}{cccccc}
1 & 1 & 1 & 1 & 1 & 1 \\
\hline 0 & 25 & 50 & 75 & 100 & 125 \\
& & Frequency, $\mathrm{Hz}$ & &
\end{tabular}

Figure 3-2d. Distribution of Minimum Frequency

Range for $\mathrm{z}-\mathrm{W}$ Quadrant 


\section{TUBE IDENTIFICATION}

$$
\begin{aligned}
& 1-11 \\
& 12-9 \\
& 42-3 \\
& 51-116 \\
& 72-125 \\
& 87-37 \\
& 96-78 \\
& 101-04 \\
& 117-08 \\
& 119-03 \\
& 128-93 \\
& 77-01 \\
& 77-04 \\
& 77-08 \\
& 14-69 \\
& 13-69 \\
& 12-68 \\
& 42-110 \\
& 40-113 \\
& 39-114
\end{aligned}
$$

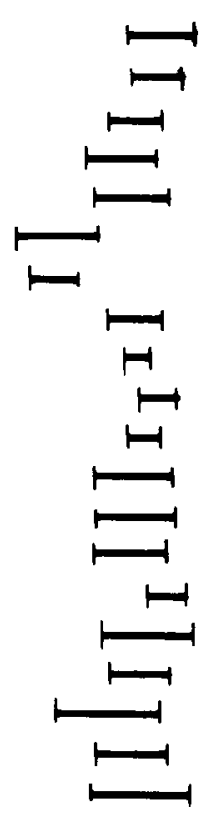

$132-81$

148-01

$150-06$

$151-16$

$151-09$

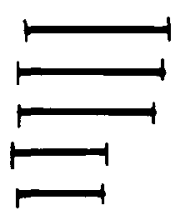

75

50

100

125

Frequency, $\mathrm{Hz}$

Figure 3-3. Distribution of Minimum Frequency Range for Peripheral Tube Within 10 Rows of Outside 


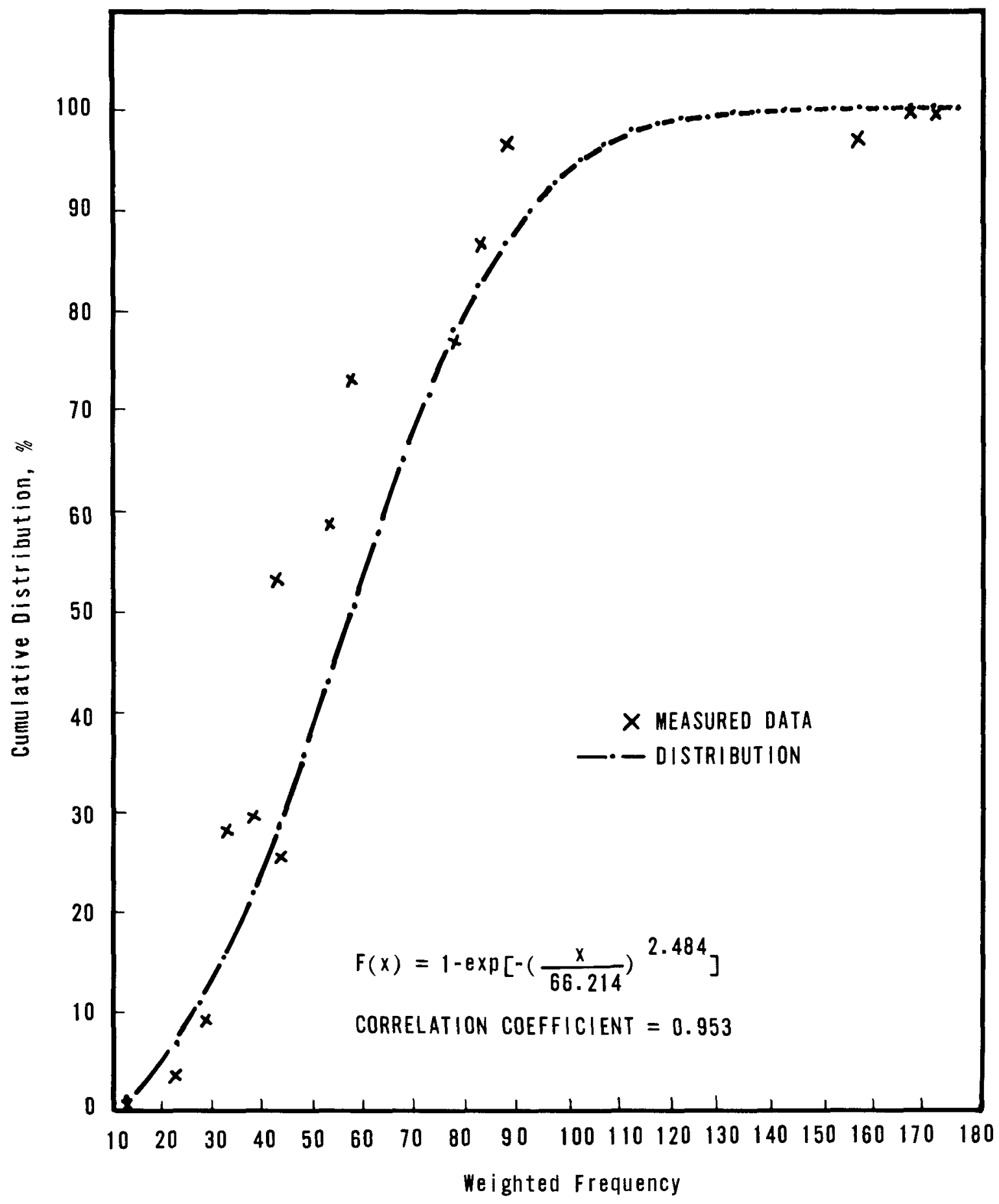

Figure 3-4. Weighted Distribution of Minimum Response Frequency 
TABLE INSTRUMENTED TUBE

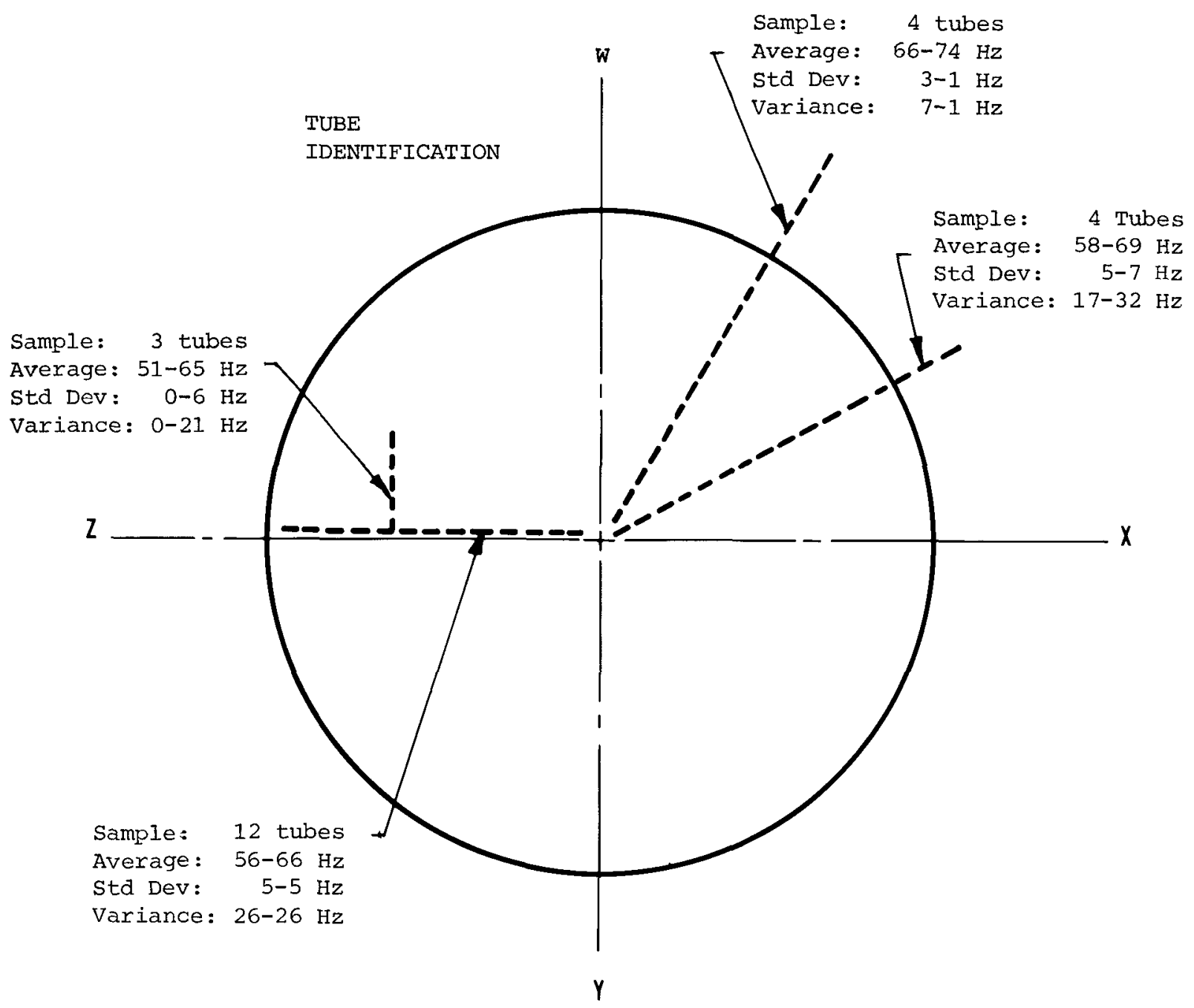

Figure 3-5. Frequency Distribution of Bandwidth for Instrumented Locations 


\section{TUBE IDENTIFICATION LANE}

$$
\begin{aligned}
& 77-01 \\
& 77-04 \\
& 77-08 \\
& 77-15 \\
& 77-19 \\
& 77-21 \\
& 77-23 \\
& 77-30 \\
& 77-35 \\
& 77-40 \\
& 77-50 \\
& 77-13
\end{aligned}
$$

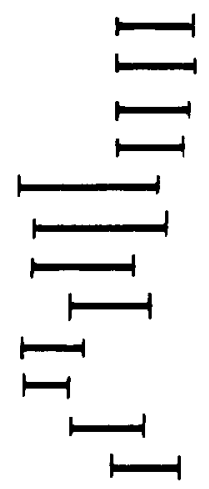

PERPENDICULAR TO LANE

$71-19$

$73-19$

$75-19$

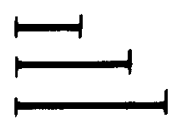

$30^{\circ}$ TO "W" AXIS

$29-76$

$14-76$

$13-69$

$12-68$

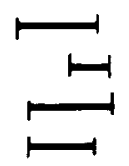

$60^{\circ}$ TO "W" AXIS

49-103

$42-110$

$40-113$

$39-114$

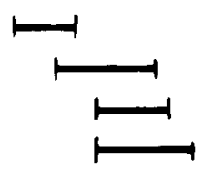

\begin{tabular}{cccccc}
1 & 1 & 1 & 1 & 1 & 1 \\
\hline 0 & 25 & 50 & 75 & 100 & 125 \\
& & & Frequency, $\mathrm{Hz}$ & &
\end{tabular}

Figure 3-6. Distribution of Minimum Frequency Range for Instrumented Locations 


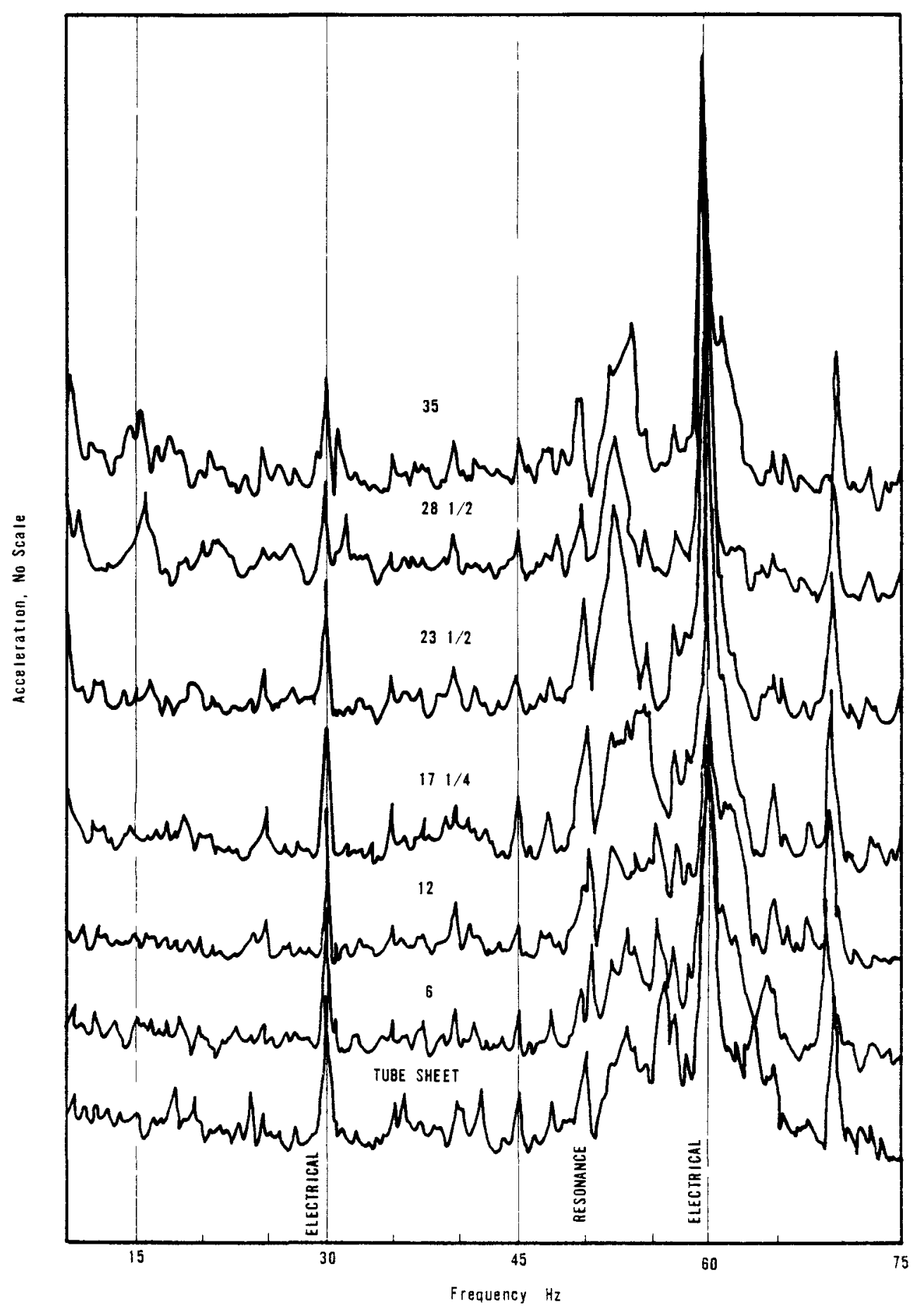

Figure 3-7. Spectral Response of Tube 77-035 Fixed Accelerometer 


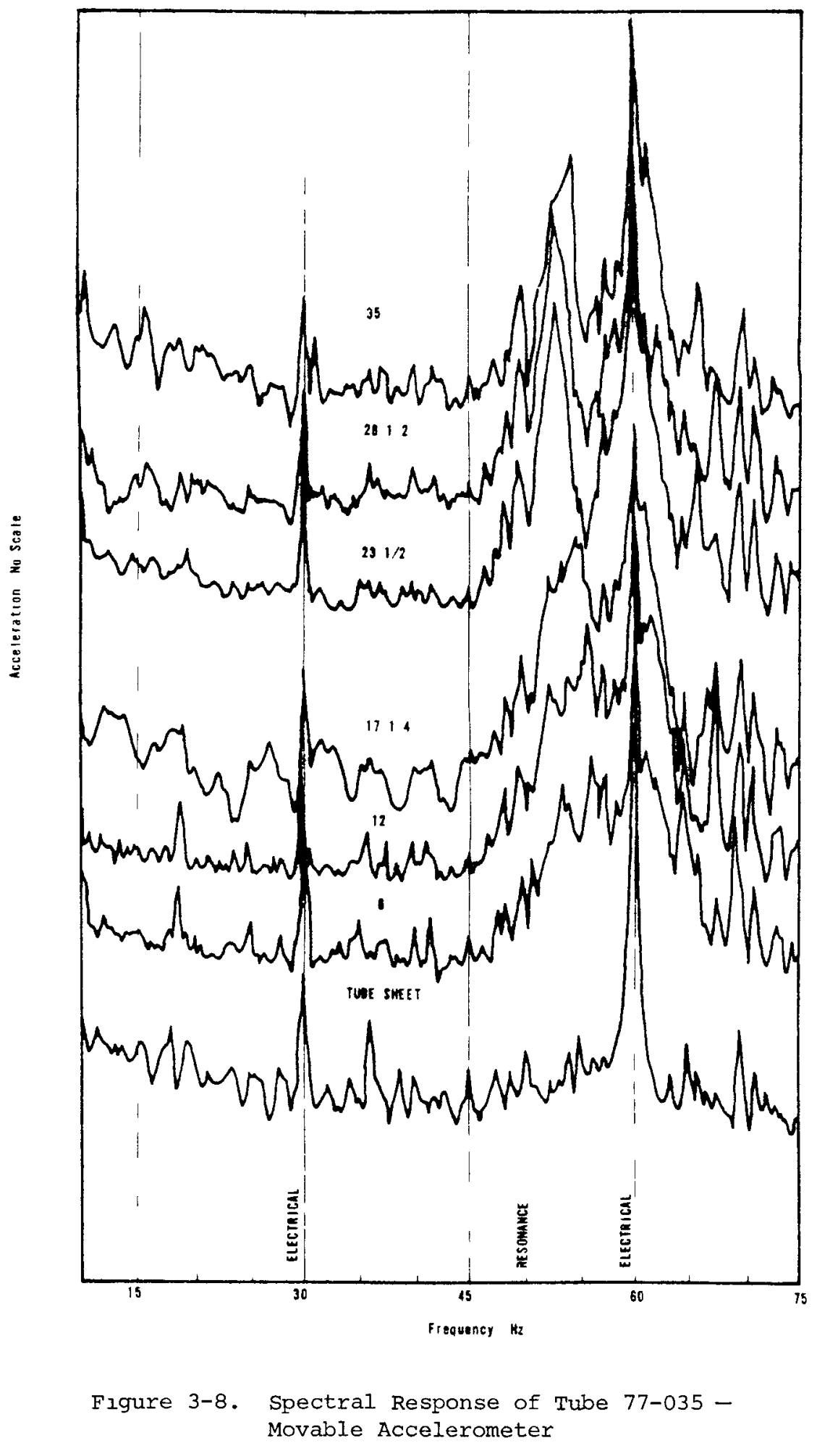




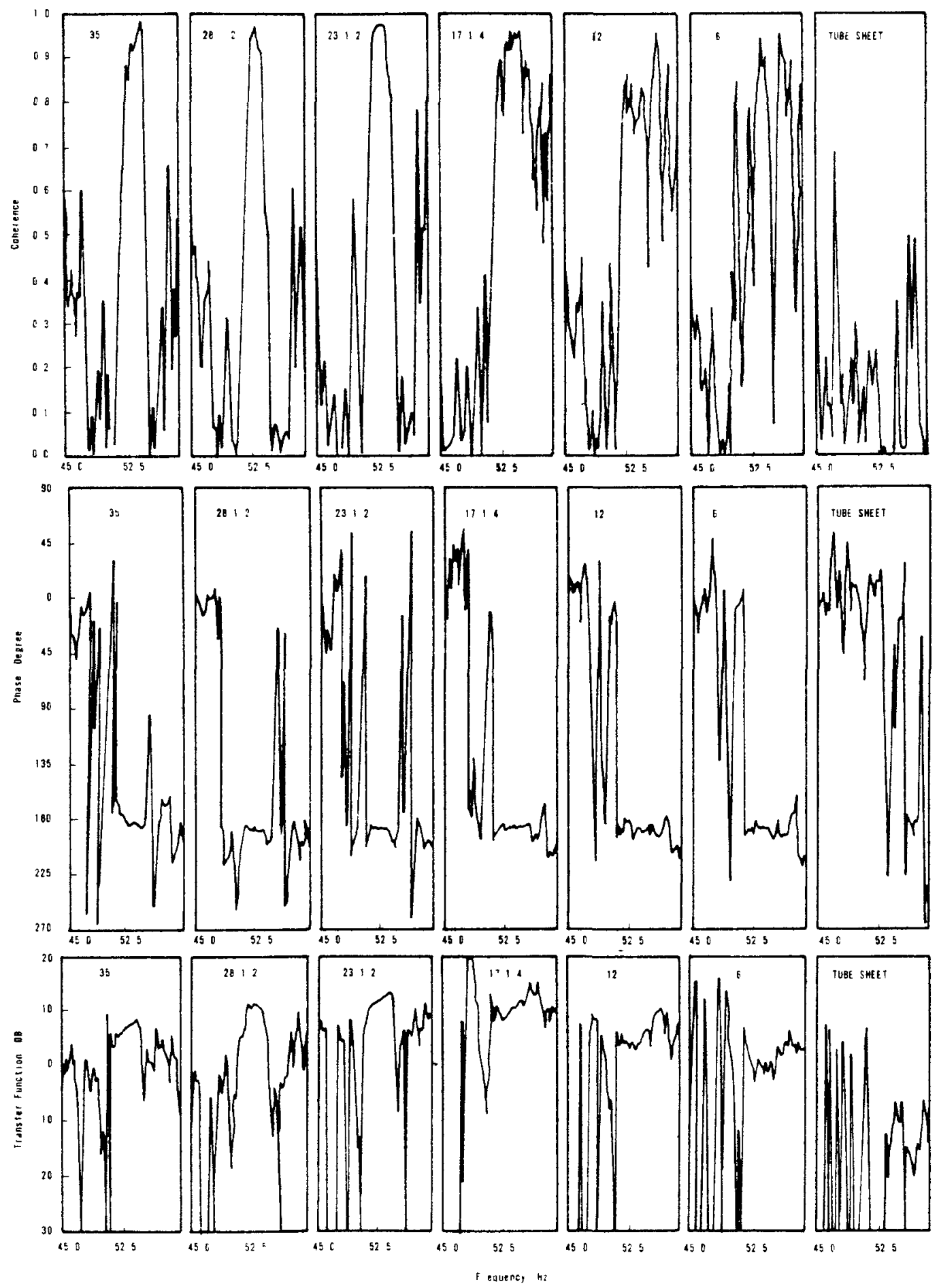

Figure 3-9. Spectral Cross Properties of Paired Measurement Locations 


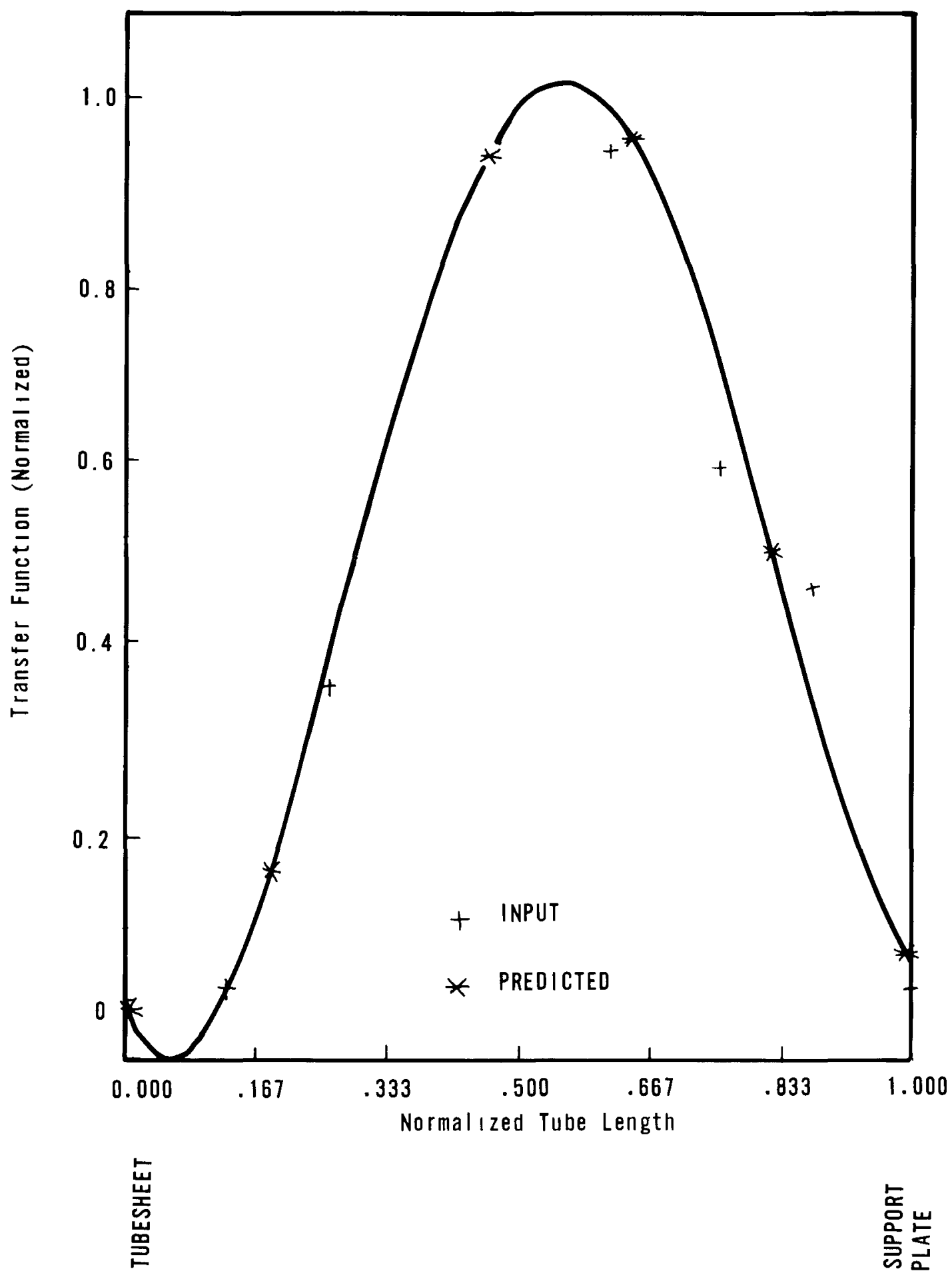

Figure 3-10a. Mode Shape for Tube 77-035 with Corresponding Resonant Frequency $52 \mathrm{~Hz}$ 


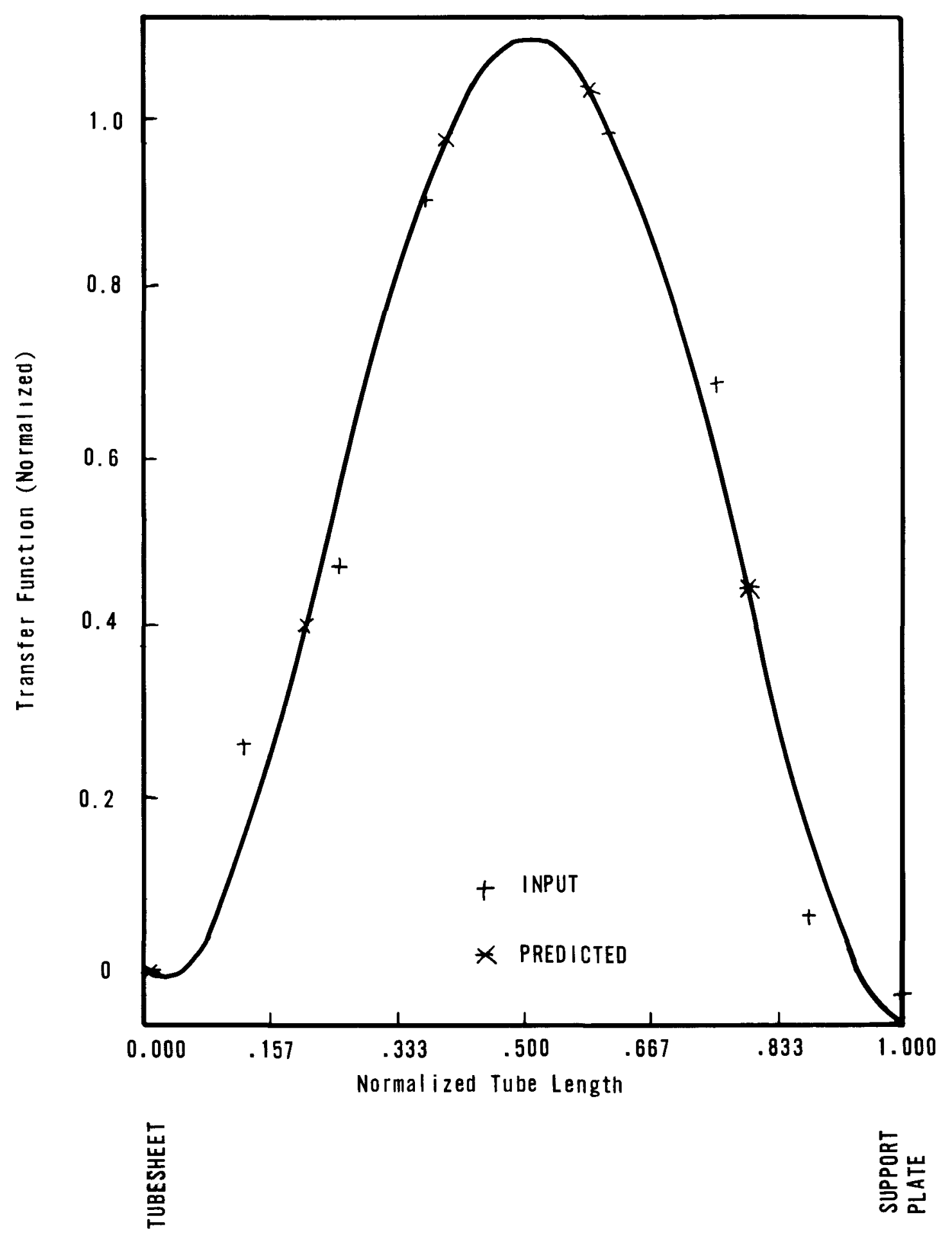

Figure 3-10b. Orthogonal Mode Shape for Tube 77-035 with Corresponding Resonant Frequency $53 \mathrm{~Hz}$ 


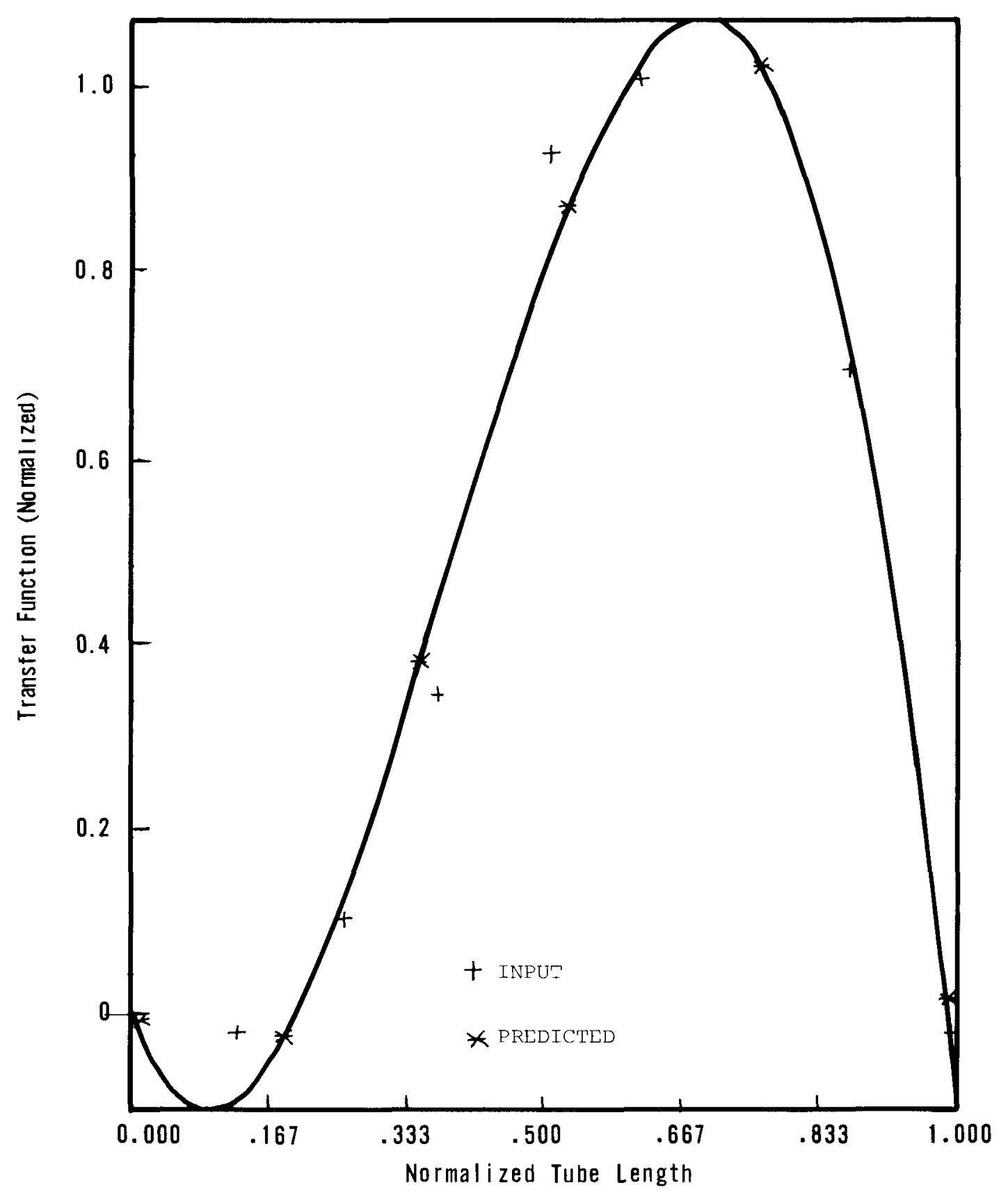

蓣
岁

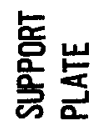

Figure 3-10c. Mode Shape for Tube 77-035 With Corresponding Resonant Frequency $63 \mathrm{~Hz}$

$3-21$ 


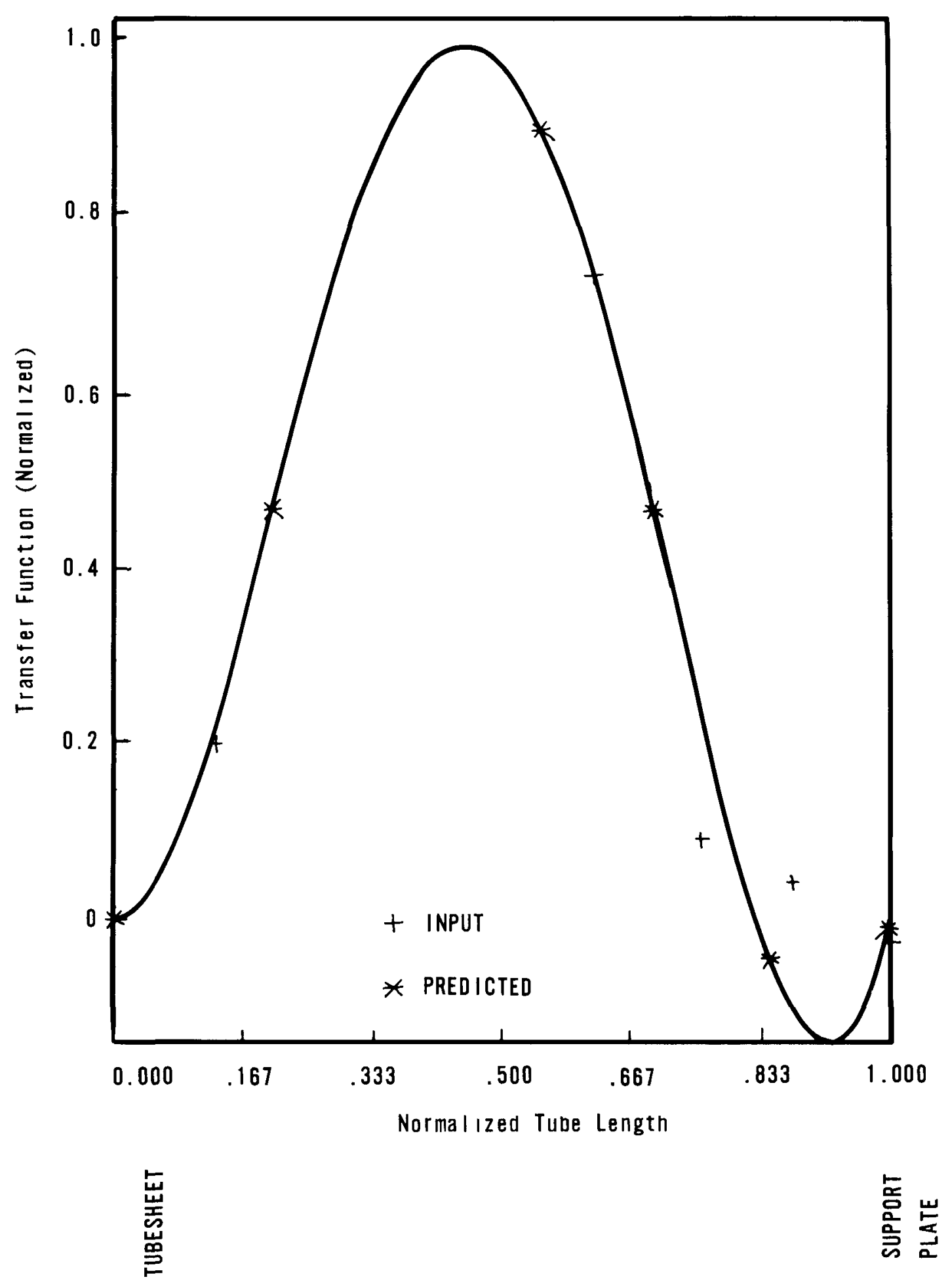

Figure 3-10d. Orthogonal Mode Shape for Tube 77-015 with Corresponding Resonant Frequency $62 \mathrm{~Hz}$ 


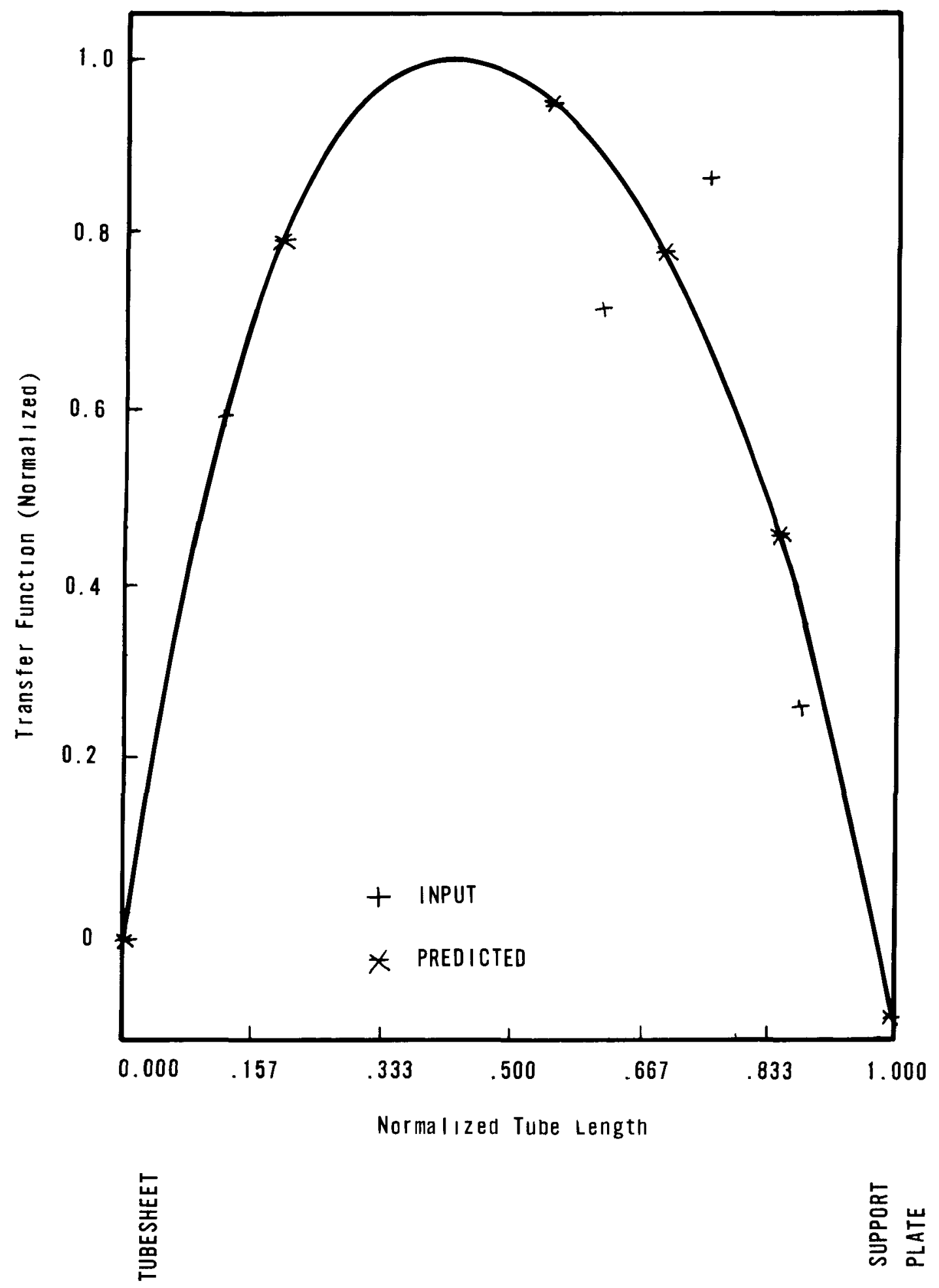

Figure 3-10e. Mode Shape for Tube 71-019 with Corresponding Resonant Frequency $52 \mathrm{~Hz}$ 


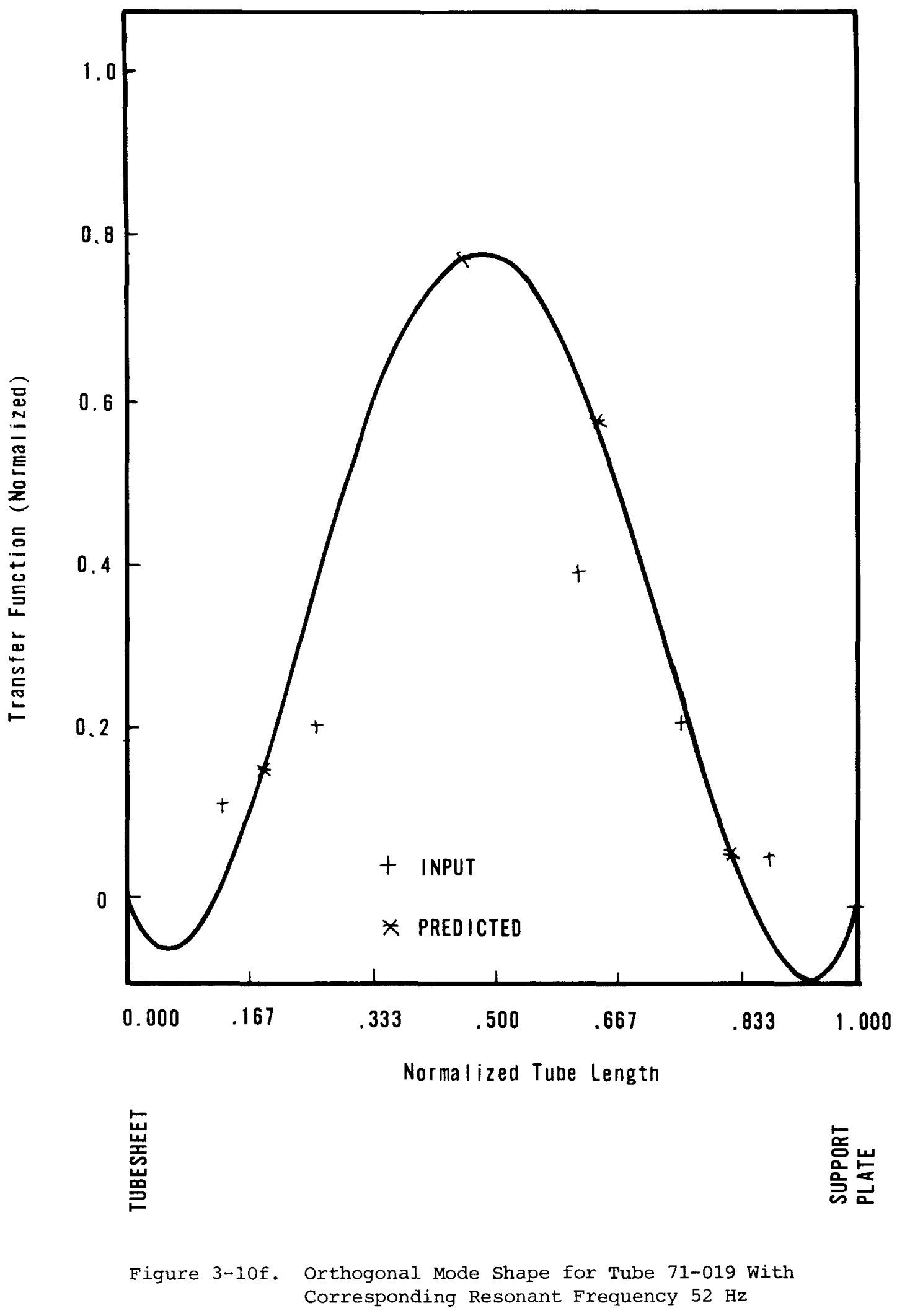




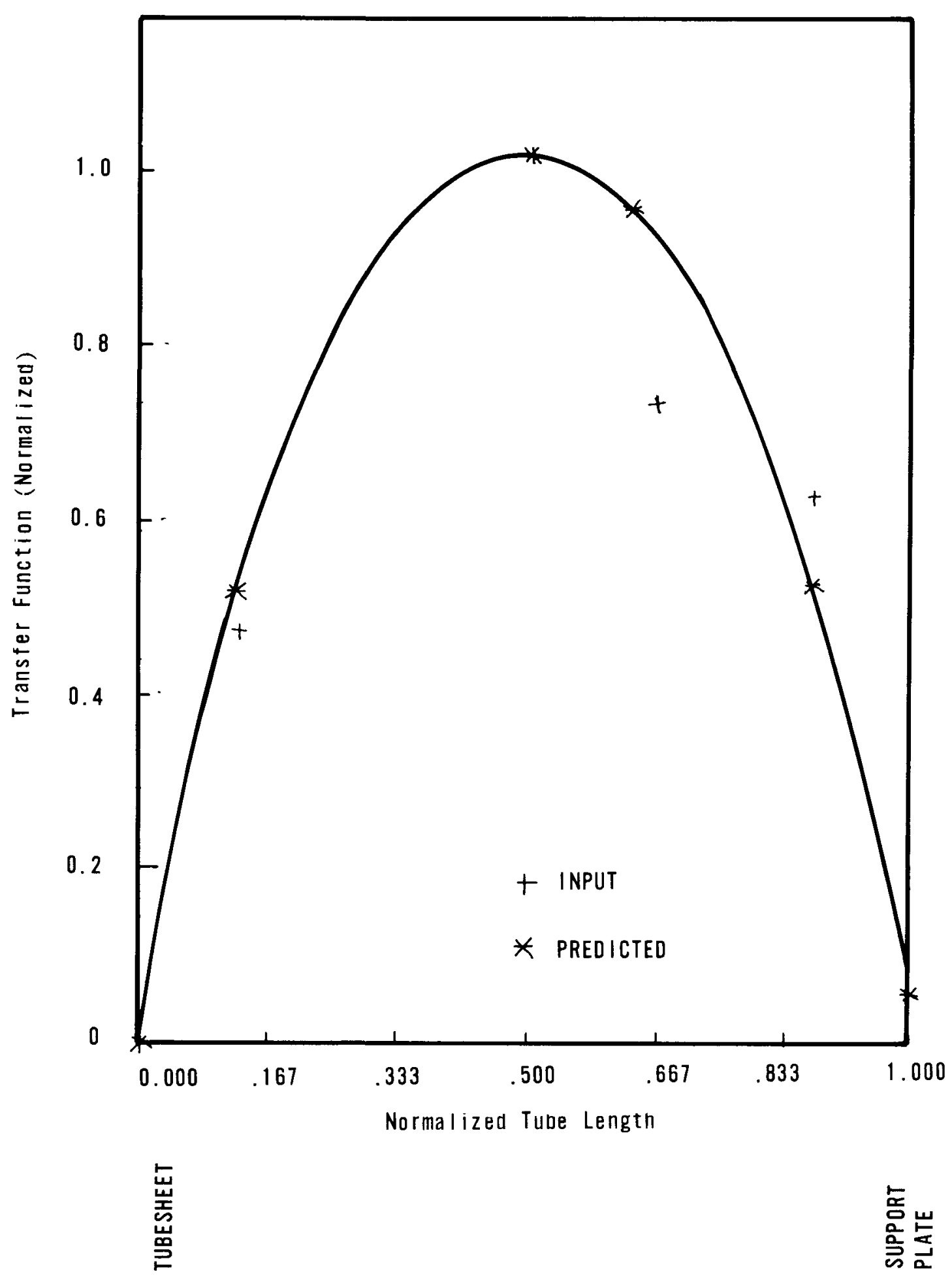

Figure 3-10g. Mode Shape for Tube 39-114 with Corresponding Resonant Frequency $65 \mathrm{~Hz}$

$3-25$ 


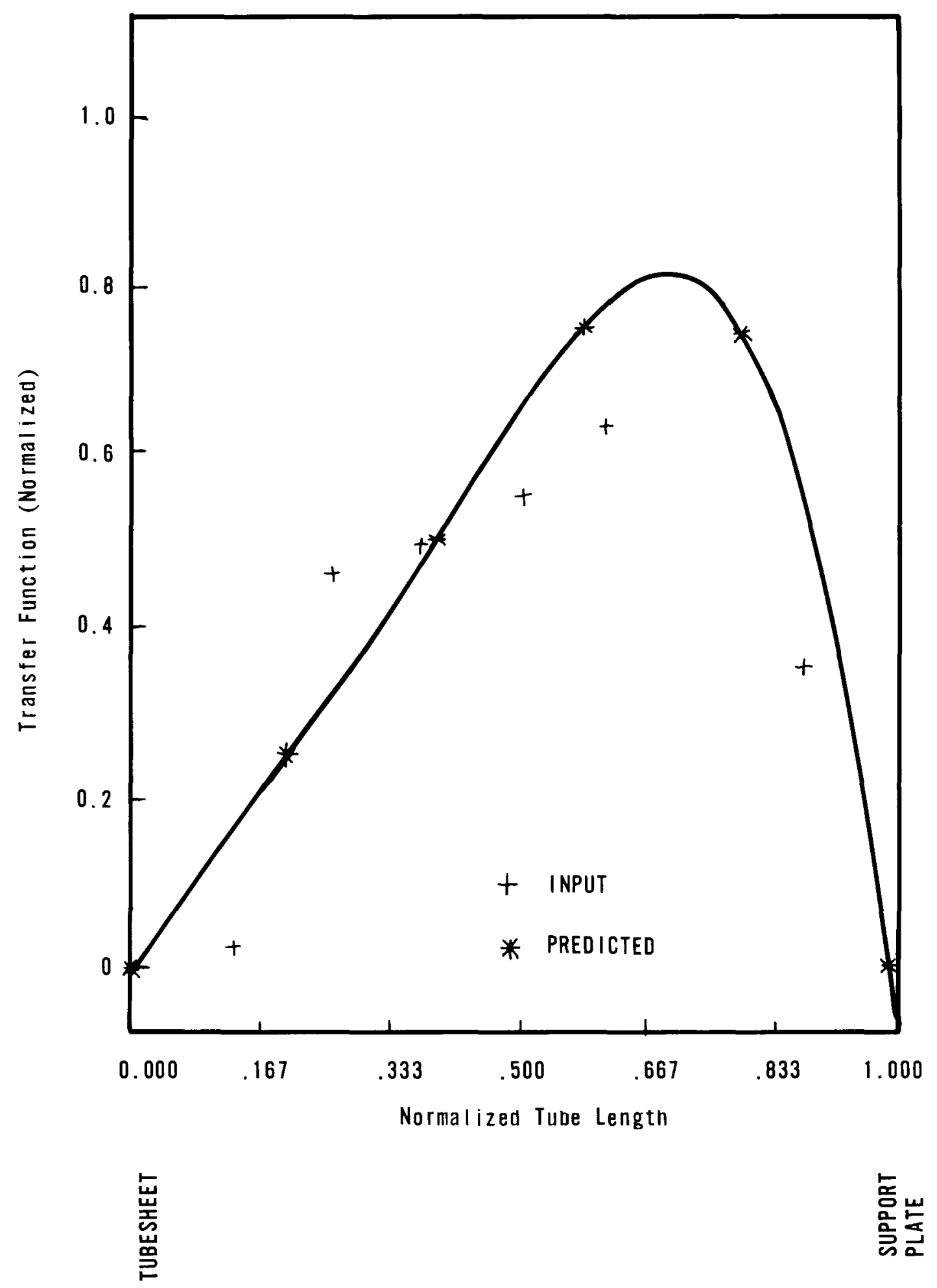

Figure 3-10h. Orthogonal Mode Shape for Tube 39-114 with Corresponding Resonant Frequency $65 \mathrm{~Hz}$ 


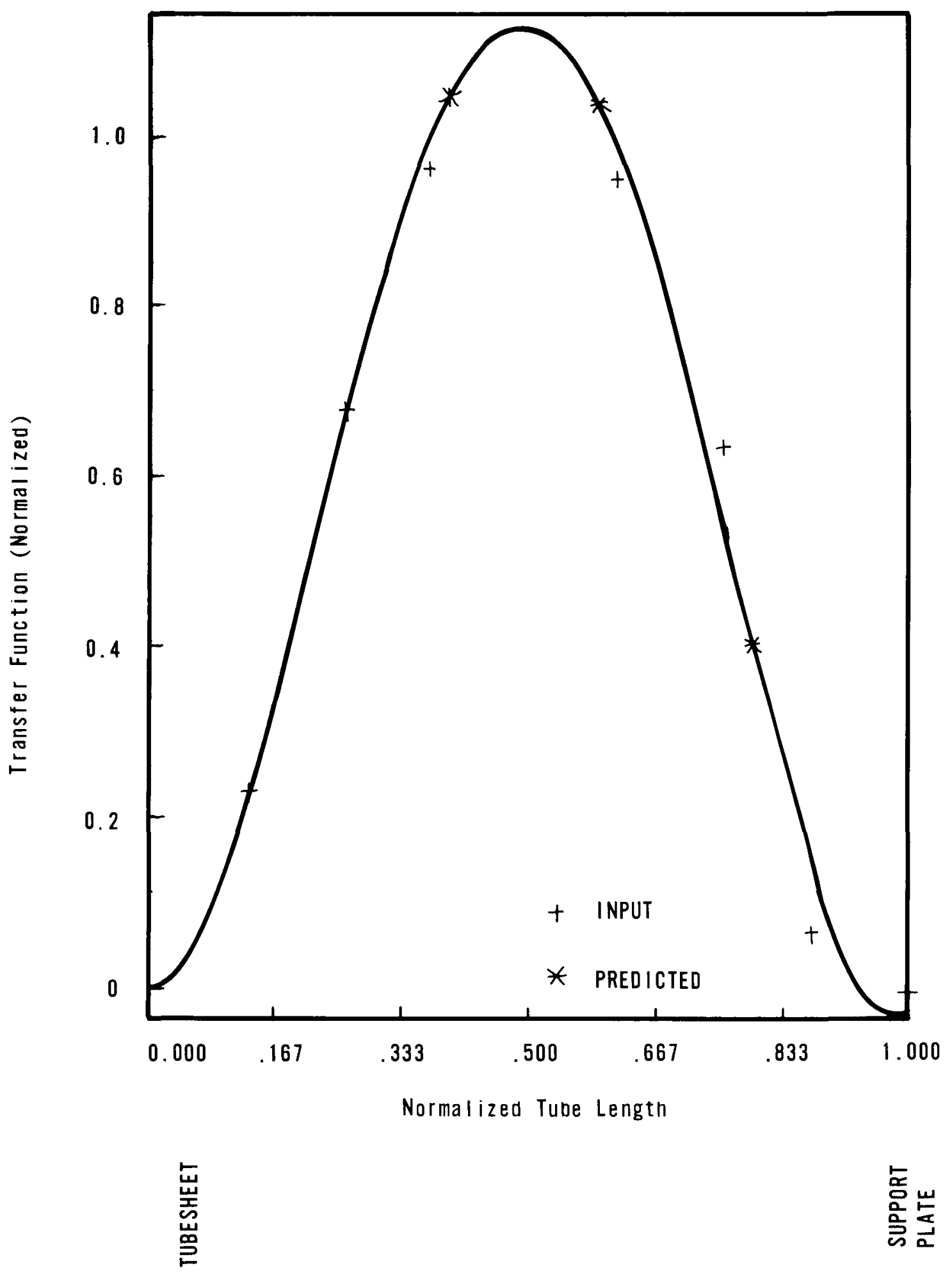

Figure 3-10i. Mode Shape for Tube 13-069 With Corresponding Resonant Frequency $66 \mathrm{~Hz}$ 


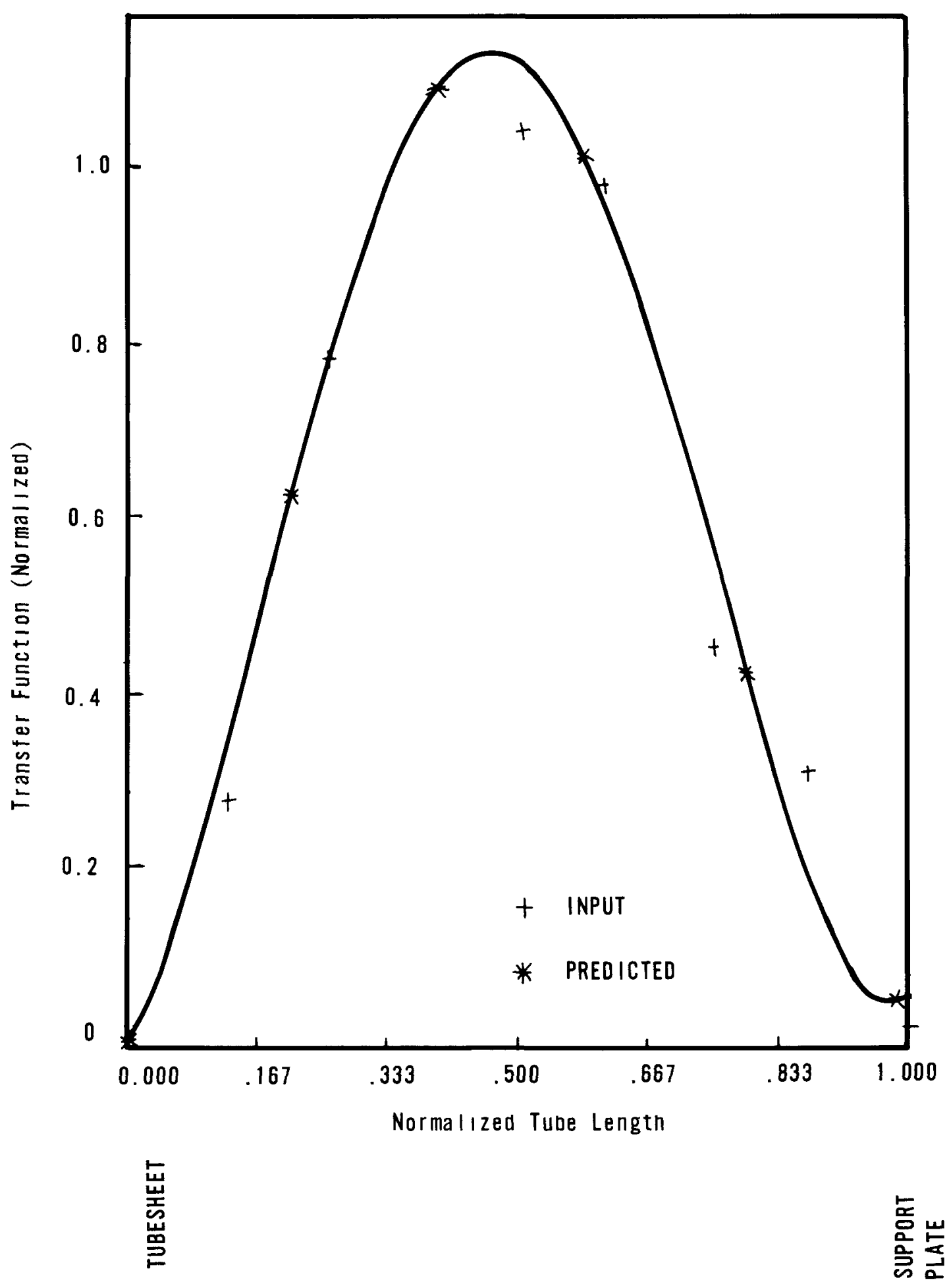

Figure 3-10]. Orthogonal Mode Shape for Tube 13-069 With Corresponding Resonant Frequency $69 \mathrm{~Hz}$

$3-28$ 


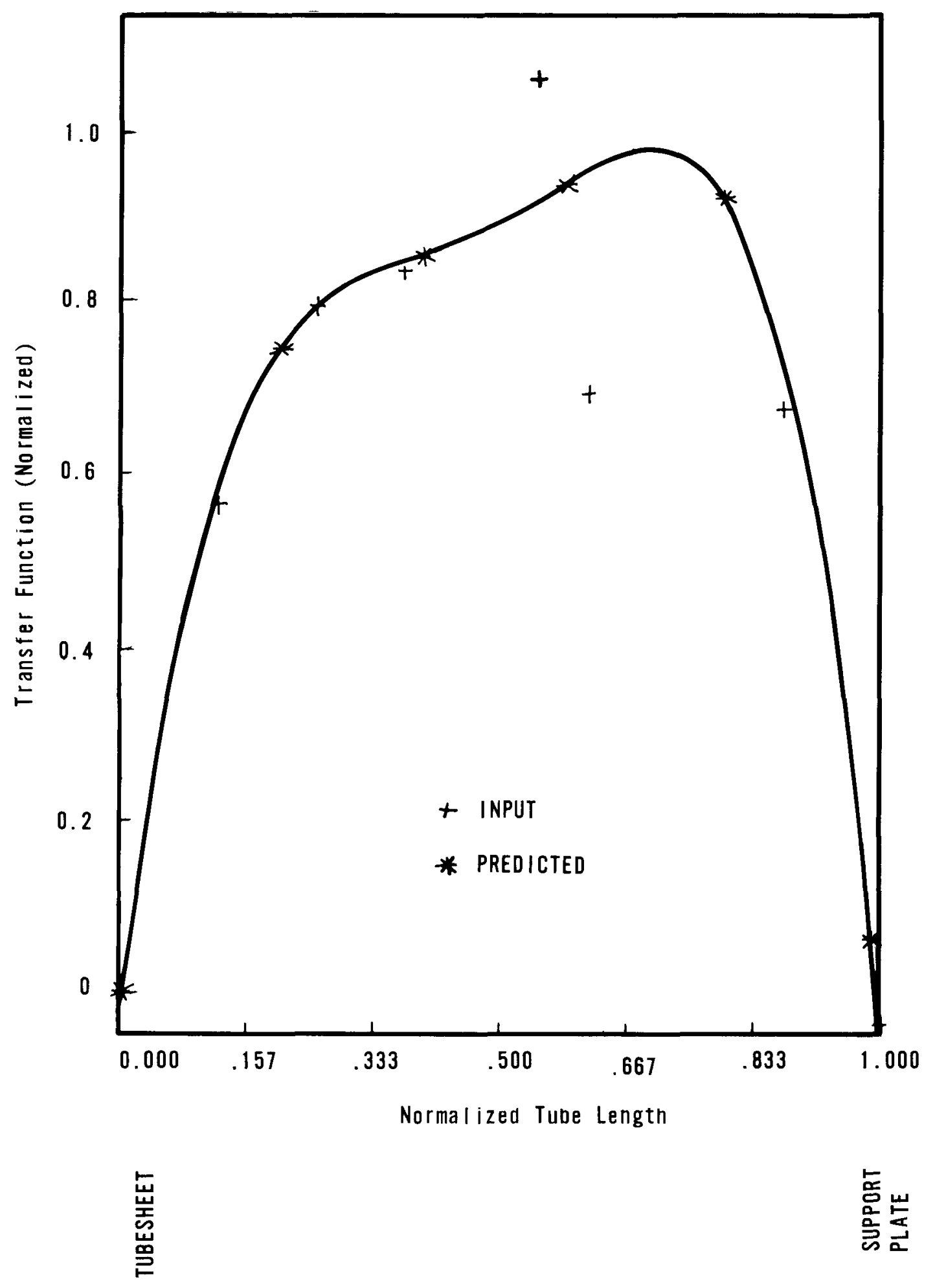

Figure 3-10k. Mode Shape for Tube 12-068 (Ninth/Tenth Span) with Corresponding Resonant Frequency $53 \mathrm{~Hz}$ 


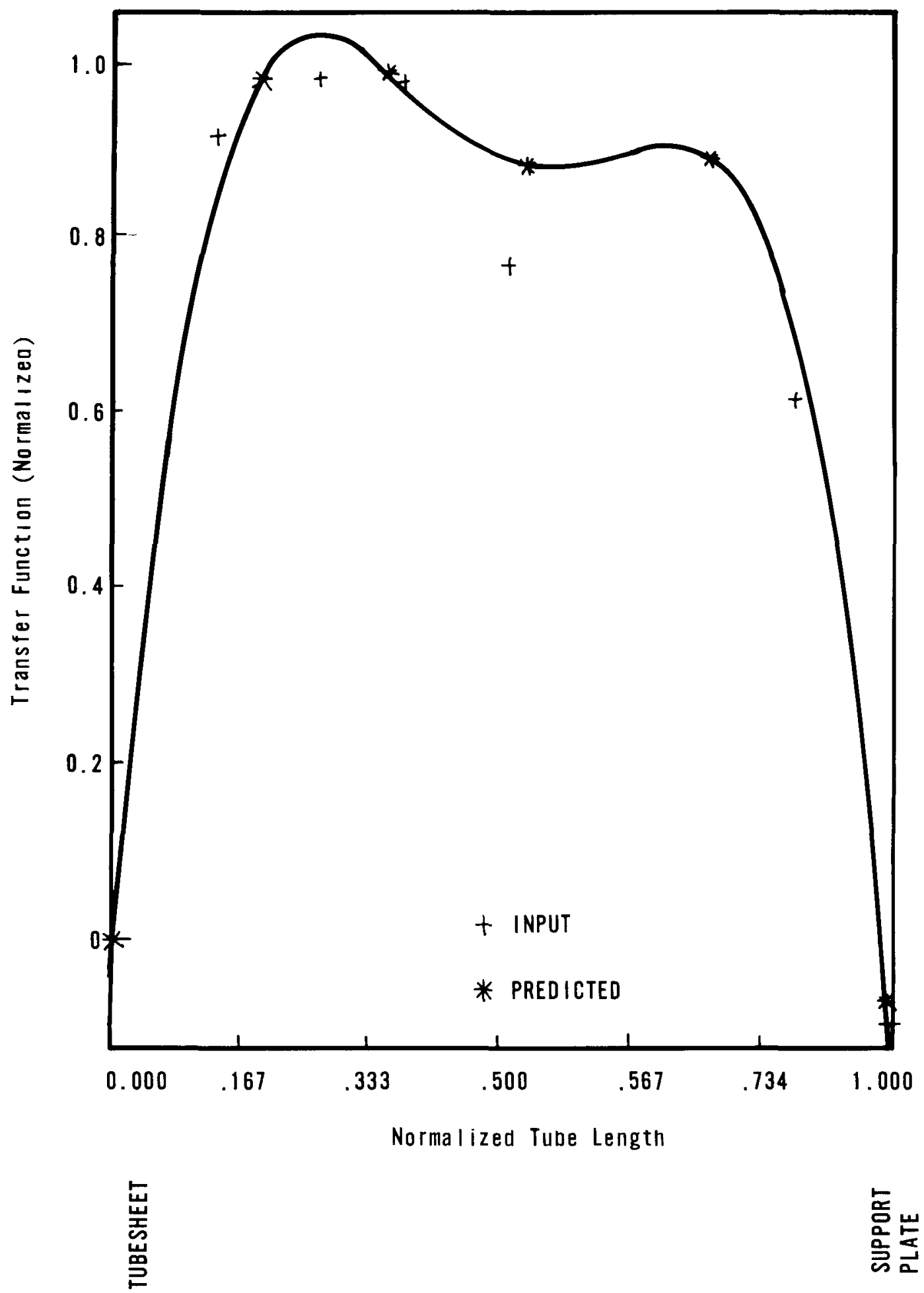

Figure 3-10l. Orthogonal Mode Shape for Tube 12-068 (Ninth/Tenth Span) With Corresponding Resonant Frequency $53 \mathrm{~Hz}$ 


\section{TUBE IDENTIFICATION}

$12-068$

$29-076$

$39-114$

49-103

$73-019$

$77-001$

$73-019$

$77-019$

$77-035$

$77-040$

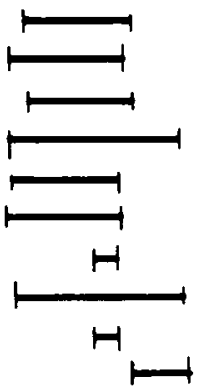

\begin{tabular}{cccccc}
1 & 1 & 1 & 1 & 1 & 1 \\
\hline 0 & 25 & 50 & 75 & 100 & 125 \\
& & Frequency, $\mathrm{Hz}$ &
\end{tabular}

Figure 3-11. Minimum Frequency Range With Installed Accelerometer 


\section{Section 4 \\ DISCUSSION OF RESULTS}

\subsection{Effect of Boundary Conditions}

Figure 4-1 shows the calculated theoretical stress spectrum using a finite element model for a full-length OTSG tube built in at the upper and lower tubesheets and simply supported at the intermediate support plates. This spectrum shows a dominant spectral peak at approximately $50 \mathrm{~Hz}$ and additional small spectral peaks nearby. These additional spectral peaks result from near- and far-field coupling between the tube spans. Variations in support plate or tubesheet boundary conditions will affect the frequency and amplitude slightly.

Agreement between the theoretical spectrum (Figure 4-1) and the experimental spectra (Figures 3-7 and 3-8) appears good. The results derived from each curve show multiple frequencies near the fundamental frequency. The bandwidth of the analyzer used to reduce the experimental measurements is crucial in separating the spectral peaks within a frequency interval. A frequency span with a bandwidth smaller than the interval between peaks was used in the analyses.

Figure 4-2 compares the mode shape corresponding to the boundary conditions and frequency described for Figure 4-1 with the experimentally determined mode shape for tube 77-035 and the static deflection shape for a uniformly loaded beam with clamped end conditions. The experimental mode shape determined for tube 77-035 closely approximates a beam with clamped boundary conditions. The mode shape for the experimental data and the NASTRAN model agree near the tubesheet but diverge near the support plate, indicating that the support plate is represented by a simple support. The mode shape for the upper span of tube 77-035 is approximately a clamped condition. This result is believed to be a result of the small excitation used to produce the span response. The response of the span was not sufficient to overcome the restraint moments imposed on the tube span caused by the frictional forces and/or the forces caused by misalignment between the support plate holes and tube.

\subsection{Influence of Axial Loads}

Figure 4-3 shows the influence of an axial tensile force on the resonance ratio between the second and fundamental resonances of classically supported beams. ${ }^{3}, 4$ 
As shown, the analytical resonance ratio for classical beams is influenced by the boundary conditions and axial tensile load. Three classical combinations of boundary conditions were chosen: simply supported at both boundaries, simply supported at the boundary corresponding to the upper tubesheet, and clamped at both boundaries. The resonance ratio curves for these decrease for increasing axial tensile load.

Also shown in Figure 4-3 is the average resonance ratio 2.62 for the test data and the associated standard deviation, 0.22. Based on the test data, the analytical results suggest that a small axial tensile preload exists on the majority of the tubes; however, some tubes may be in initial compression rather than tension.

Figure 4-4 shows the influence of an axial tensile force on the value of the first and second resonant frequencies of classically supported beams. ${ }^{3}{ }^{4}$ Included in this figure are the average values of the first and second resonant frequencies of the test data, including the associated standard deviation.

From the curves in Figure 4-4, it is very difficult to establish the value of the preload that one could expect for the tubes within the OTSG. The results suggest that the magnitude of the tensile or compressive forces imposed on a tube by manufacturing depend on the mode considered. This inconsistency is attributed to the lack of true classical boundary conditions at the support plate. This finding is confirmed by the variety of mode shapes shown in Figures 3-10a through 3-10l. From these results the in-air measurements and evaluations of the tube natural frequencies alone cannot establish the preload on these tubes.

\subsection{Comparison with Other Test Results}

Table 4-1 compares the test results of in-air measurements obtained on tube spans in other OTSGs. These sources are steam generators A and B at Oconee 1, the DavisBesse 1 steam generator, and OTSG B at Oconee 2. The table shows that the ranges of natural frequencies determined for Oconee 1 and Davis-Besse 1 are lower than the resonant response frequencies in air obtained for the Oconee 2 OTSG B. Furthermore, the results from Oconee 2 are comparable to those obtained at TMI-2 for the $B$ OTSG. For both the Oconee 2 and TMI-2 tests, the resonant frequency results are higher than those obtained from Oconee 1, OTSG A, and Davis-Besse 1. 
Table 4-1. Resonant Frequencies of OTSG Tubes Previously Reported, $\mathrm{Hz}$

\begin{tabular}{|c|c|}
\hline Oconee $1 \mathrm{~A}^{5}$ & $57-62$ \\
\hline Oconee $1 \mathrm{~B}^{5}$ & $57-62$ \\
\hline Davis-Besse ${ }^{5}$ & $54-58$ \\
\hline \multicolumn{2}{|l|}{ Oconee $2 \mathrm{~B}^{6}$} \\
\hline Tube $77-19$ & $73-78$ \\
\hline $77-18$ & $65-67$ \\
\hline $77-04$ & $67-71$ \\
\hline $78-04$ & $72-75$ \\
\hline \multicolumn{2}{|l|}{$T M I-2$} \\
\hline W-X quadrant avg & $59-69$ \\
\hline $\mathrm{X}-\mathrm{Y}$ quadrant avg & $54-60$ \\
\hline $\mathrm{Y}-\mathrm{Z}$ quadrant avg & $56-68$ \\
\hline $\mathrm{Z}-\mathrm{W}$ quadrant avg & $59-69$ \\
\hline
\end{tabular}




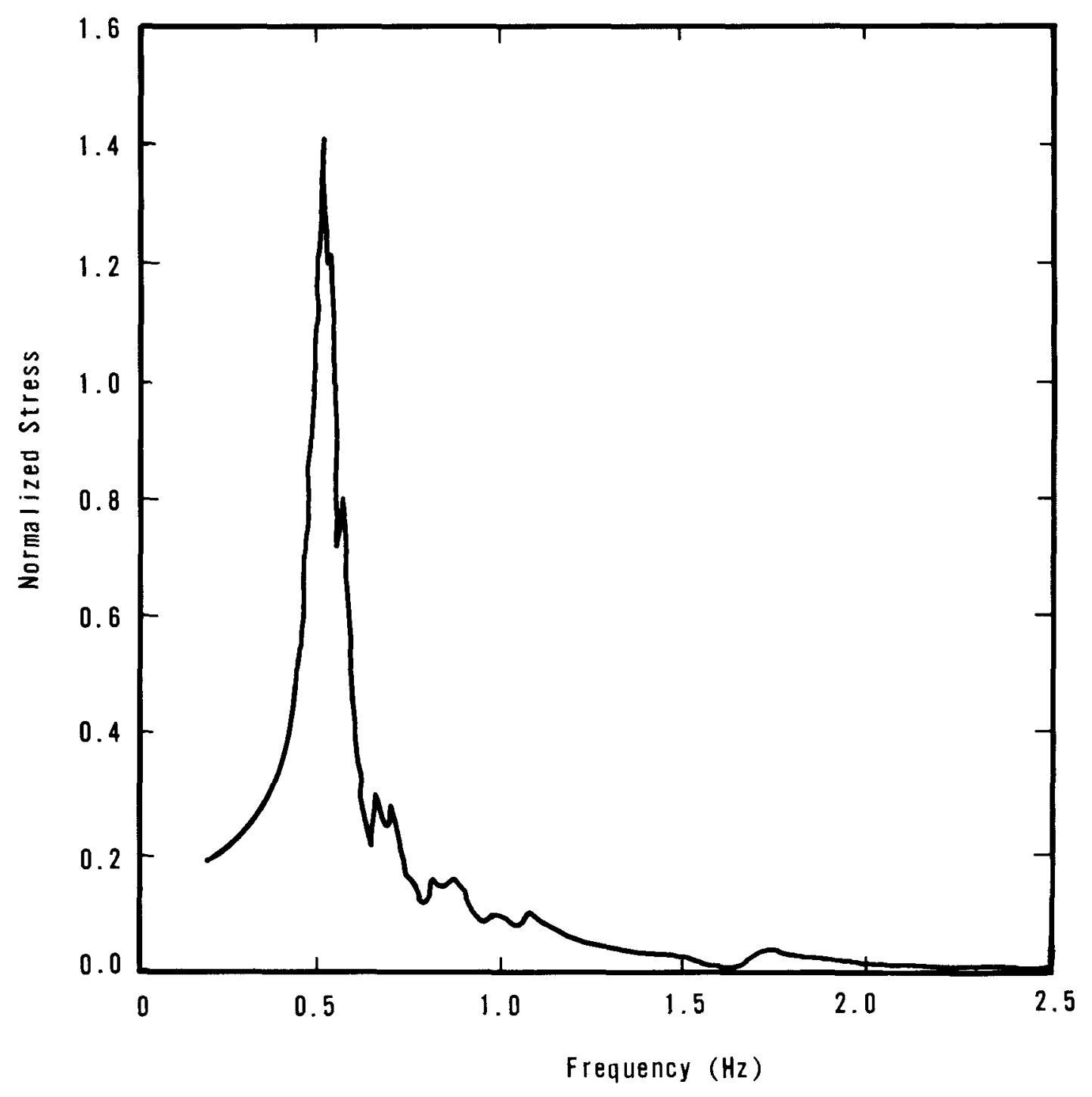

Figure 4-1. Theoretical Response Spectrum 


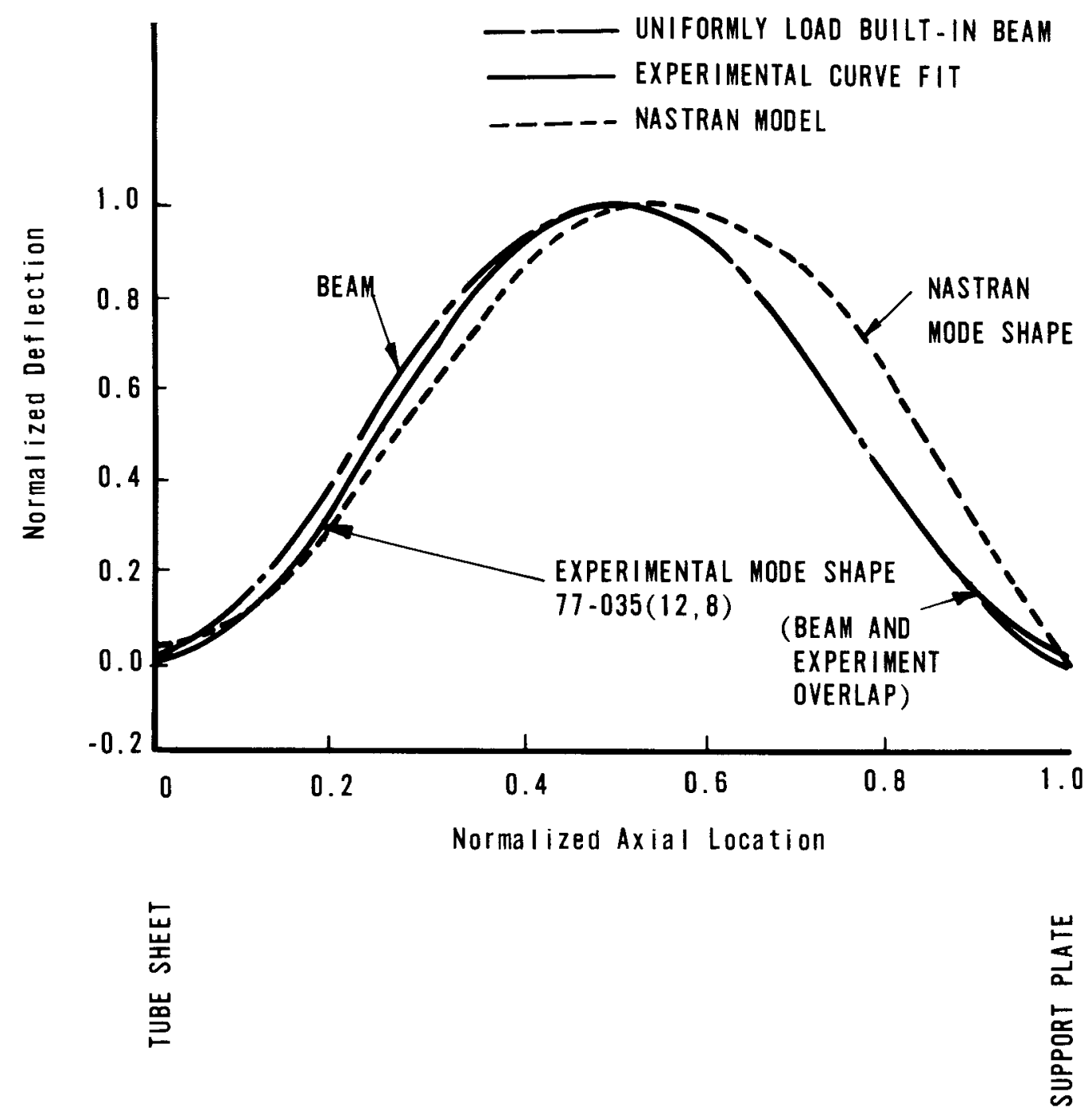

Figure 4-2. Mode Shape Comparison - Analytical and Experimental 


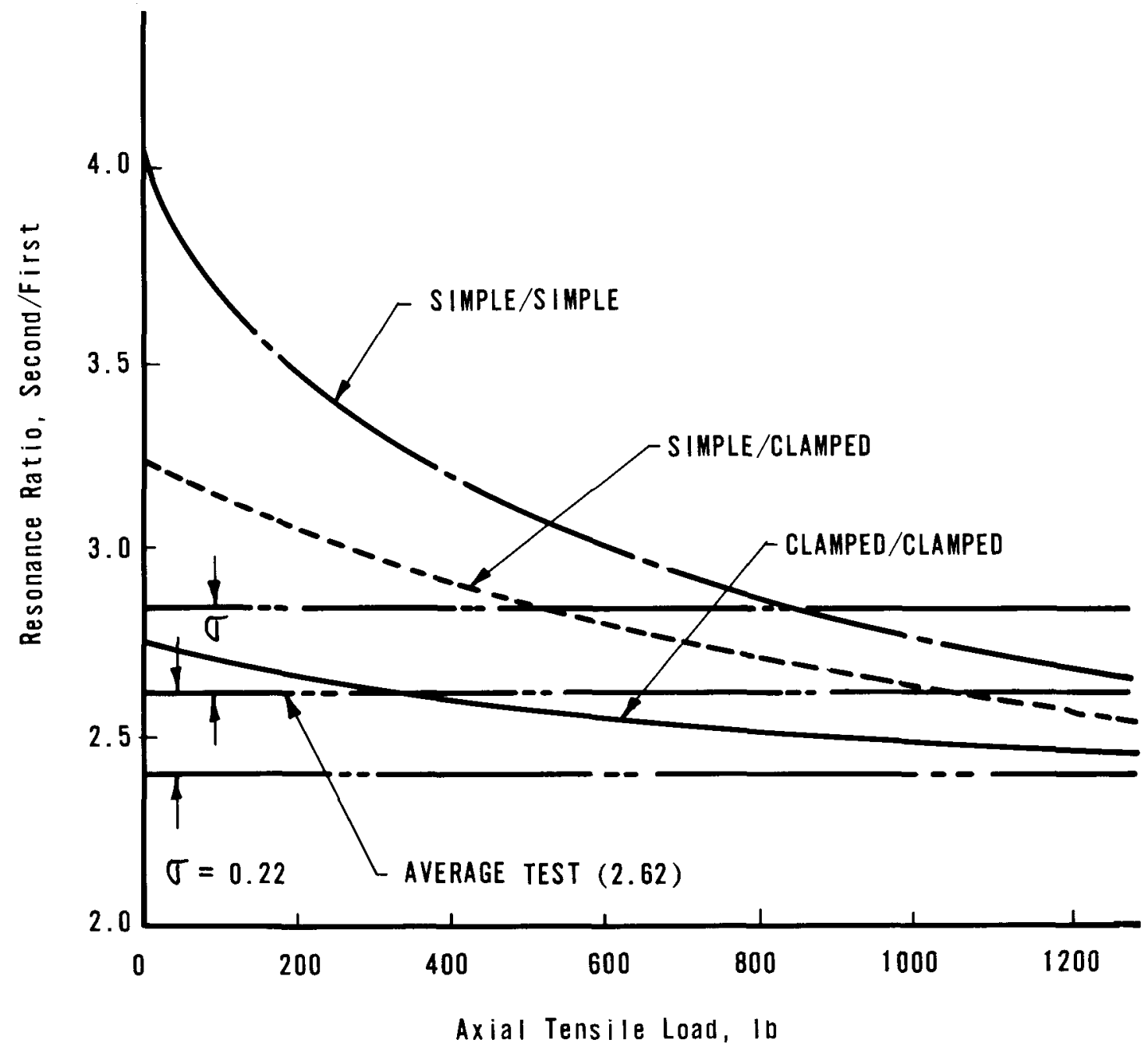

Figure 4-3. Resonance Ratio - Second/First Resonance 


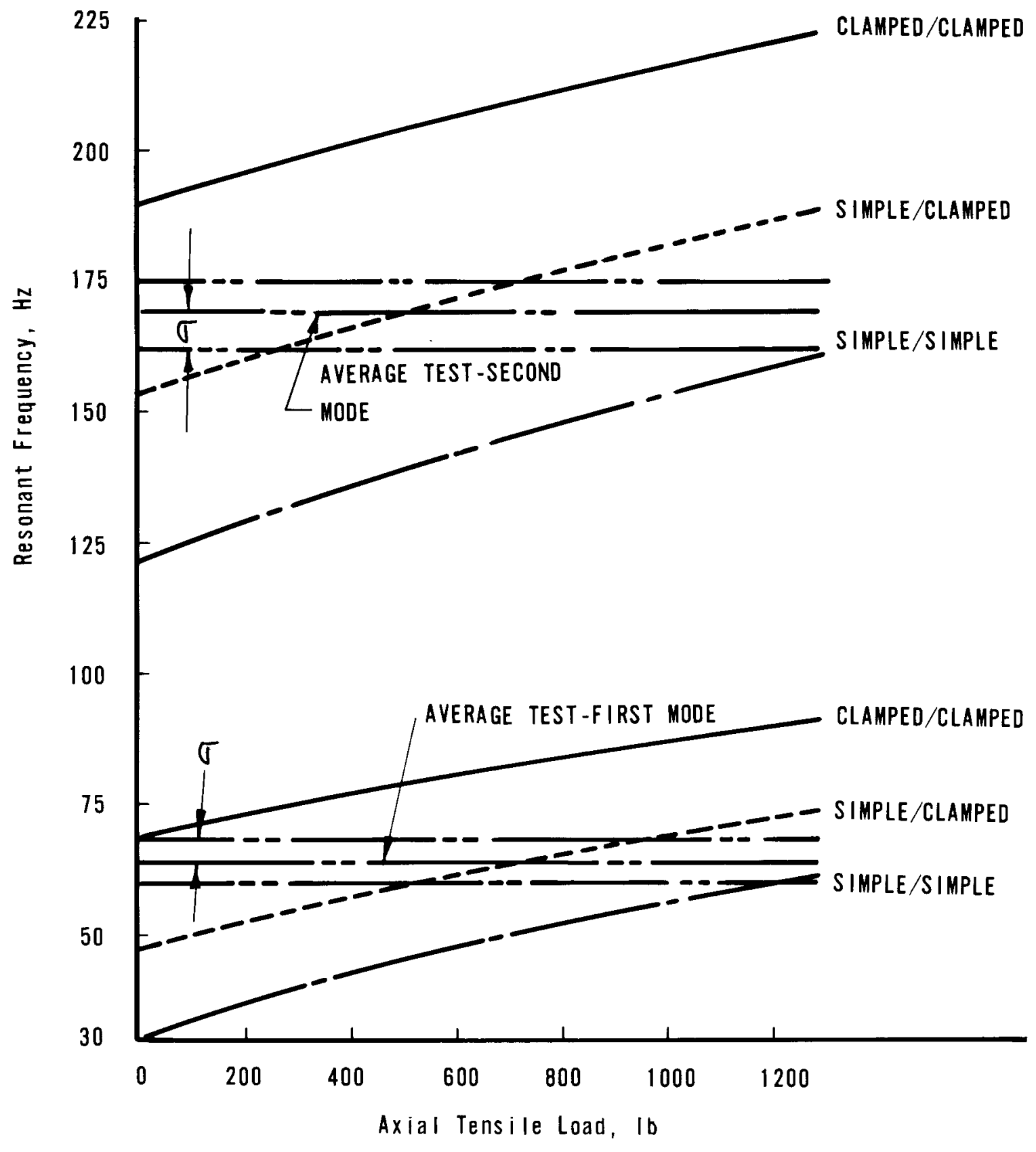

Figure 4-4. Influence of Axial Load on First and Second Resonances 
Section 5

CONCLUSIONS

Interpretation of the results from the in-air tests conducted on OTSG B at TMI- 2 led to the following conclusions:

1. The spectrum obtalned from the in-alr measurements on an indıvidual span agrees in form with those obtained from an analytical model. Both spectra contain multiple frequencies attrıbuted to near- and far-field coupling between spans.

2. The resonant response of a tube span depends on the boundary conditions. The actual boundary conditions existing in a steam generator are not classical but vary between built-in at both ends or bullt-in and simply supported with varying axial loads.

3. Variations in the boundary conditions for an actual tube in a steam generator preclude using resonant frequency measurements alone as a method of determining the amount of axial load existing in a tube. This method may be used in conjunction with other measurements which can determine boundary conditions.

4. The boundary conditions determined for a tube span from the in-alr tests are believed to be influenced by the level of the excltation force. The acoustic excitation of the tubes was small and may not have been sufficlent to overcome the moment restraint umposed on the tube span at the support plate. The support plate moments were induced by frictional forces between the tube and the support plate, misalignment between the tube and the holes In the support plate, and imperfections in the tube.

5. The resonant frequencies measured in the in-air tests at TMI-2 and Oconee 2 are similar. However, they are higher than those obtained from previously reported in-air measurements at Oconee 1 or Davis-Besse. 
Section 6

RECOMMENDATIONS

As a result of the interpretation of and conclusions from the in-air test data from the TMI-2 OTSG $B$, the following recommendations are made:

1. Much information on the structural response and vibration characteristics such as natural frequency and mode shape were obtained in this report. The results should be used as a guide in interpreting the response data from the instrumented tubes during operation.

2. The results of the in-air test provide much valuable information on the structural behavior of a large number of steam generator tubes. The method of transfer function, phase, and coherence used to determine the mode shape of various tube spans should be adapted for use in other programs where mode shapes of complex structures in the presence of random vibration are desired.

3. The damping mechanism and damping values of the tubes tested in air should be determined and compared with the hot operating results. This comparison can be used in developing and expanding analytical models of steam generator tubes. 

Section 7

REFERENCES

1 Flow-Induced Vibration Analysis of Three Mile Island Unit-2, Once-Through Steam Generator Tubes, EPRI S 140-1, Vol. 1, June 1981.

2 J. C. Simonis, "Modal Analysis of a Cylindrical Shell Excited by Axial Flow," presented at 1978 SESA Spring Meeting, Wichita, Kansas.

3 D. J. Gorman, Free Vibration Analysis of Beams and Shafts, John Wiley \& Sons, New York, pp 362-365.

4 W. T. Thompson, Vibration Theory and Applications, Prentice-Hall (1965).

5 J. M. Neilsen, et al., Tube Pluck Test Results - Oconee OTSG Units A and B Toledo Units (Barberton Works), ON 6328-73, Babcock \& Wilcox, Alliance, Ohio, November 27,1972 .

6 J. C. Simonis, Results From the Oconee 2B Once-Through Steam Generator Field Measurements Program, NPGD-TM-434, Babcock \& Wilcox, Lynchburg, Virginia, January 1978. 


\section{APPENDIX A}

TMI-2 In-Air Test procedure

Prepared by: J. M. Huzdovich

Nuclear Services

Reviewed by: J. C. Simonis

Applied Mechanics

Technical staff

Reviewed by: J. W. Mitchem

$10 / 26 / 77$

Task Engineer

OTSG Field Measurement Program

Approved by: L. H. Bohn, Manager

$10 / 26 / 77$

Reactor Internals Unit

Note: This procedure has been retyped for clarity without changes to the content. 


\section{Purpose}

1.1. To identify the mode shape and resonant frequency of the topmost span of each instrumented OTSG tube.

1.2. To identify the mode shape and resonant frequency of the span between the ninth and tenth support plates of selected tubes.

1.3. To identify typical mechanical characteristics of OTSG tubes based on a random sample.

\section{References}

2.1. Field Measurement Test Program of a Once-Through Steam Generator at Three Mile Island Unit 2, Section 5.2. J. C. Simonis, Applied Mechanics Unit.

2.2. Field Change Package No. 147 for TMI-2.

\section{Prerequisites}

3.1. Preparations for OTSG access complete including removal of primary side upper head manway and inspection covers, lower head manway and inspection covers, and secondary side upper she11 and shroud manway covers.

3.2. Measurement of ID of strain gauge tubes complete and all instrumented tubes marked as per reference 2.2 .

3.3. ECE trailer setup and electric power connections completed.

3.4. Signal and communication wiring pulled and terminated from reactor building J-box on " $\mathrm{W}$ " side of OTSG B to ECE trailer and to the OTSG lower head area. Electrical checks complete.

3.5. All items of required equipment assembled, checked out, and ready for use.

3.6. Power and light available at upper and lower tubesheet areas and at the secondary side manway area.

\section{Test Equipment}

See Attachment 1. 
5. Procedure

Note: The Site Test Engineer may alter the sequence of this procedure and add or delete steps to improve data quality assurance or test efficiency.

\subsection{Preparations}

5.1.1. Unpackage five accelerometers and feed through primary side inspection opening one at a time. Attach retrieval lines and place on tubesheet below hand hole. (Attachment 7)

5.1.2. Route connector end of the cable for these five to the J-box and terminate to the line drivers. Secure cable so that there is no stress on the connector.

5.1.3. Unpackage remaining three accelerometers and pass into the OTSG. Do not uncoil.

5.1.4. Mount the excitation mechanism on the upper OTSG secondary side manway as shown by Attachment 6, sheet 1 .

5.1.5. Calibrate the individual components of the electronic test equipment in the B\&W Memorial Avenue Shop and interconnect these components as indicated by Attachment 2. Field calibration will be performed only on those components that fail the channel operational check. Procedures are the B\&W shop procedure or as per vendor instruction manual.

5.1.6. Verify operability of biaxial accelerometers by checking $100-\mathrm{Hz}$ response (utilize signal channels, shaker, and observe PSD).

5.1.7. Check all sensor channels and establish signal level settings by transducer substitution method. (Attachment 3)

5.2. OTSG Tube Characteristization Upper Span Mode Shape

5.2.1. Insert two biaxial accelerometers in each of the first three tubes indicated in Attachment 5 using the method specified in Attachment 7.

5.2.2.1. Engineering to verify location of tubes.

5.2.2.2. Install one accelerometer $4.5 \pm 0.25$ inches below the bottom surface of the upper tubesheet and the 
second $34.75 \pm 0.25$ inches below the bottom surface of the upper tubesheet.

5.2.1.3. During installation, ensure that axes of the accelerometers are aligned with each other.

5.2.2. Excite the tubes iwth the excitation mechanism.

5.2.2.1. Site Test Engineer to judge acceptability of raw data.

5.2.2.2. Check all channels for proper response and signal levels. Response to be checked by spectral analysis.

5.2.3. Proceed with test if raw data are accepted and record ciata for 10 minutes.

5.2.4. Repeat steps $5 \cdot 2.2$ and 5.2 .3 for all locations specified in Table 1 .

5.2.5. Remove the biaxial accelerometers one at a time until all have been removed using the method specified in Attachment 7 .

5.2.6. Repeat steps 5.2.1 through 5.2.4 until a11 23 locations have been tried.

5.2.7. Mark tapes "Upper Span Mode Shape" IAT-TMI-2, date, attach tube-tape matrix (Attachment 5), and turn over to the Site Test Engineer.

5.3. OTSG Tube Characterization Ninth/Tenth Span Mode Shape

5.3.1. Insert two biaxial accelerometers in each tube 12-68 and 39-114 using the method specified in Attachment 7.

5.3.1.1. Engineering to verify location of tubes.

5.3.1.2. Insta11 one accelerometer at $258.25 \pm 0.5$ inches below the lower surface of the upper tubesheet and the second $253.25 \pm 0.5$ inches below the lower surface of the upper tubesheet.

5.3.1.3. During installation, ensure that the axes of the accelerometers are aligned with each other.

5.3.2. Excite tubes by means of the excitation mechanism. If the speaker does not excit the tubes, use the Wilcoxon vibration generator and stud coupler, Attachment 6 , sheet 2 . 
5.3.2.1. Site Test Engineer to judge acceptability of raw data.

5.3.2.2. Check all channels for proper response and signal levels. Response to be checked by spectral analysis.

5.3.3. Proceed with test if raw data are accepted and record data for 10 minutes.

5.3.4. Repeat steps 5.3 .2 and 5.3 .3 for all locations specified in Table 2 .

5.3.5. Remove the biaxial accelerometers using the method specified in Attachment 7.

5.3.6. Mark tapes "Ninth/Tenth Span Mode Shape," IAT-TMI-2, date, and turn over to the Site Test Engineer.

\subsection{OTSG Tube Characterization -}

Random Sample

5.4.1. Install six biaxial accelerometers, using the accelrometer installation tool, in the first six tubes identified in Attachment 4 to a depth of $12.5 \pm 0.25$ inches below the bottom of the upper tubesheet, per Attachment 7 .

5.4.1.1. Engineering to verify location of tubes.

5.4.1.2. From outside of OTSG at primary side hand hole, feed through sufficient cable as the accelerometers are inserted into the tubes.

5.4.2. Excite tubes by means of the excitation mechanism.

5.4.2.1. Site Test Engineer to judge acceptability of raw data.

5.4.2.2. Check all channels for proper response and signal levels. Response to be checked by spectral ana1ysis.

5.4.3. Proceed with test if raw data are accepted and record data for 10 minutes.

5.4.4. Remove the biaxial accelerometers one at a time until a11 have been removed.

5.4.5. Repeat steps 5.2.1 through 5.2.4 until all 100 locations have been tried. 
5.4.6. Mark tapes "Random Sample," IAT-TMI-2, date, attach tube tape matrix (Attachment 4), and turn over to the Site Test Engineer.

\section{Acceptance Criteria}

6.1. Contamination by $60 \mathrm{~Hz}$ power line noise does not interfere with determination of tube resonant frequencies as determined by the Site Test Engineer.

6.2. Signal levels sufficiently above electronic noise floor for processing, as determined by the Site Test Engineer.

6.3. Accelerometer orientation, location, and tape channel assignment data acceptable to the Site Test Engineer. 
Table 1. Modal Test Positions - Upper Span Mode Shape

(a)

\begin{tabular}{|c|c|c|c|c|}
\hline \multirow[b]{2}{*}{ Test } & \multicolumn{2}{|c|}{ Reference accelerometer } & \multicolumn{2}{|c|}{ Movable accelerometer } \\
\hline & $\begin{array}{c}\text { From bottom } \\
\text { of UTS }\end{array}$ & $\begin{array}{l}\text { From top } \\
\text { of tube }\end{array}$ & $\begin{array}{c}\text { From bottom } \\
\text { of UTS }\end{array}$ & $\begin{array}{c}\text { From top of } \\
\text { tube }\end{array}$ \\
\hline 1 & 40.5 & 65 & In tubesheet & In tubsheet \\
\hline 2 & 40.5 & 65 & 6 & 30.50 \\
\hline 3 & 40.5 & 65 & 12 & 36.50 \\
\hline 4 & 40.5 & 65 & 17.25 & 41.75 \\
\hline 5 & 40.5 & 65 & 23.50 & 48.0 \\
\hline 6 & 40.5 & 65 & 28.50 & 53.0 \\
\hline 7 & 40.5 & 65 & 34.75 & 59.25 \\
\hline
\end{tabular}

(a) Note: A11 locations are given in inches, and tolerance is \pm 0.25 inch.

\begin{tabular}{|c|c|c|}
\hline Test & $\begin{array}{c}\text { Reference } \\
\text { accelerometer } \\
\text { axis } \\
\end{array}$ & $\begin{array}{c}\text { Movable } \\
\text { accelerometer } \\
\text { axis } \\
\end{array}$ \\
\hline \multirow[t]{2}{*}{1} & $X$ & $\mathrm{X}$ \\
\hline & $\mathrm{Y}$ & $\mathrm{Y}$ \\
\hline \multirow[t]{2}{*}{2} & - & $\mathrm{X}$ \\
\hline & - & $\mathrm{Y}$ \\
\hline \multirow[t]{2}{*}{3} & - & $\mathrm{X}$ \\
\hline & - & $Y$ \\
\hline \multirow[t]{2}{*}{4} & - & $\mathrm{X}$ \\
\hline & - & $Y$ \\
\hline \multirow[t]{2}{*}{5} & - & $\mathrm{x}$ \\
\hline & - & $Y$ \\
\hline \multirow[t]{2}{*}{6} & - & $\mathrm{X}$ \\
\hline & - & $\mathrm{Y}$ \\
\hline \multirow[t]{2}{*}{7} & - & $\mathrm{X}$ \\
\hline & - & $\mathrm{Y}$ \\
\hline
\end{tabular}

Note: Align axes to coincide with OTSG $\mathrm{W}-\mathrm{Y}$ and $\mathrm{X}-\mathrm{Z}$ axes. 
Table 2. Modal Test Positions - Ninth/Tenth Span Mode Shape ${ }^{(a)}$

\begin{tabular}{|c|c|c|c|c|}
\hline \multirow[b]{2}{*}{ Test } & \multicolumn{2}{|c|}{ Reference accelerometer } & \multicolumn{2}{|c|}{ Movable accelerometer } \\
\hline & $\begin{array}{l}\text { From bottom } \\
\text { of UTS }\end{array}$ & $\begin{array}{l}\text { From top } \\
\text { of tube } \\
\end{array}$ & $\begin{array}{l}\text { From bottom } \\
\text { of UTS } \\
\end{array}$ & $\begin{array}{l}\text { From top } \\
\text { of tube } \\
\end{array}$ \\
\hline 1 & 258.5 & 283 & 228.5 & 253 \\
\hline 2 & 258.5 & 283 & 233.5 & 258 \\
\hline 3 & 258.5 & 283 & 238.5 & 263 \\
\hline 4 & 258.5 & 283 & 243.5 & 268 \\
\hline 5 & 258.5 & 283 & 248.5 & 273 \\
\hline 6 & 258.5 & 283 & 253.5 & 278 \\
\hline
\end{tabular}

(a) All locations are given in inches, and tolerance is \pm 0.25 inch.

\begin{tabular}{|c|c|c|}
\hline Test & $\begin{array}{c}\text { Reference } \\
\text { accelerometer } \\
\text { axis } \\
\end{array}$ & $\begin{array}{c}\text { Movable } \\
\text { accelerometer } \\
\text { axis }\end{array}$ \\
\hline \multirow[t]{2}{*}{1} & $\mathrm{x}$ & $\mathrm{x}$ \\
\hline & $\mathrm{Y}$ & $Y$ \\
\hline \multirow[t]{2}{*}{2} & & $x$ \\
\hline & & $\mathrm{Y}$ \\
\hline \multirow[t]{2}{*}{3} & & $X$ \\
\hline & & $Y$ \\
\hline \multirow[t]{2}{*}{4} & & $\mathrm{X}$ \\
\hline & & $\mathrm{Y}$ \\
\hline \multirow[t]{2}{*}{5} & & $\mathrm{X}$ \\
\hline & & $Y$ \\
\hline \multirow[t]{2}{*}{6} & & $X$ \\
\hline & & $Y$ \\
\hline
\end{tabular}

Note: Align axes to coincide with OTSG $\mathrm{W}-\mathrm{Y}$ and $\mathrm{X}-\mathrm{Z}$ axes. 
1. Biaxial accelerometers, Columbia Mode1

2. Line driver, Endevco $2731 \mathrm{~B}$ 16

3. Charge amplifier, Endevco 2735

4. Filters, Kronhite Mode1 3202

5. Tape recorder

6. Mag tape, Ampex 14 in.

7. Spectrum analyzer, SD 335

8. Scope, Tektronix 7613

9. Vibration generator and power supp1y, Wilcoxon

10. White noise generator, Wavetech ModeI 132

11. Time code generator, Systron Donner Mode1 8350

12. Accelerometer installation tool, Engineering

13. Plumb line, Engineering

14. Speaker, woofer $100 \mathrm{~W}$-RMS

15. Speaker mount, Nuclear Service

16. Stud coupler, Nuclear Service

17. Drop lights, extension cords, GPU

18. Interconnecting cable
a. 16 TSP, GPU
b. Charge amp to filters, 16 coax
$10 \mathrm{ft}$
c. Filters to tape, 16 coax
$10 \mathrm{ft}$
d. Filters to SD 335 and scope, 4 coax
$10 \mathrm{ft}$
e. Time code genertor to tape, 2 coax
$10 \mathrm{ft}$
$f$. White noise generator-vibration generator, PS by vendor

19. BNC hardware

As needed
a. Tees
b. Binding post adapters

20

20

20. Equipment table

3

21. Shaker, Unholtz-Dickie and General Radio 1557A

1 each

22. Accelerometer, Endevco 2273AM20

2

23. X-Y plotter

1

24. Strap wrench

1

25. Precision capacitor

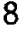
8 (6) 2

1

1

1


Attachment 1 (Cont'd)

Quantity

26. DVM 1

27. FM calibrator, Bel1 \& Howel1 type 13-555

1

28. Gneral Radio megohm bridge

1

29. Multimeter, Simpson

1 
Attachment 2

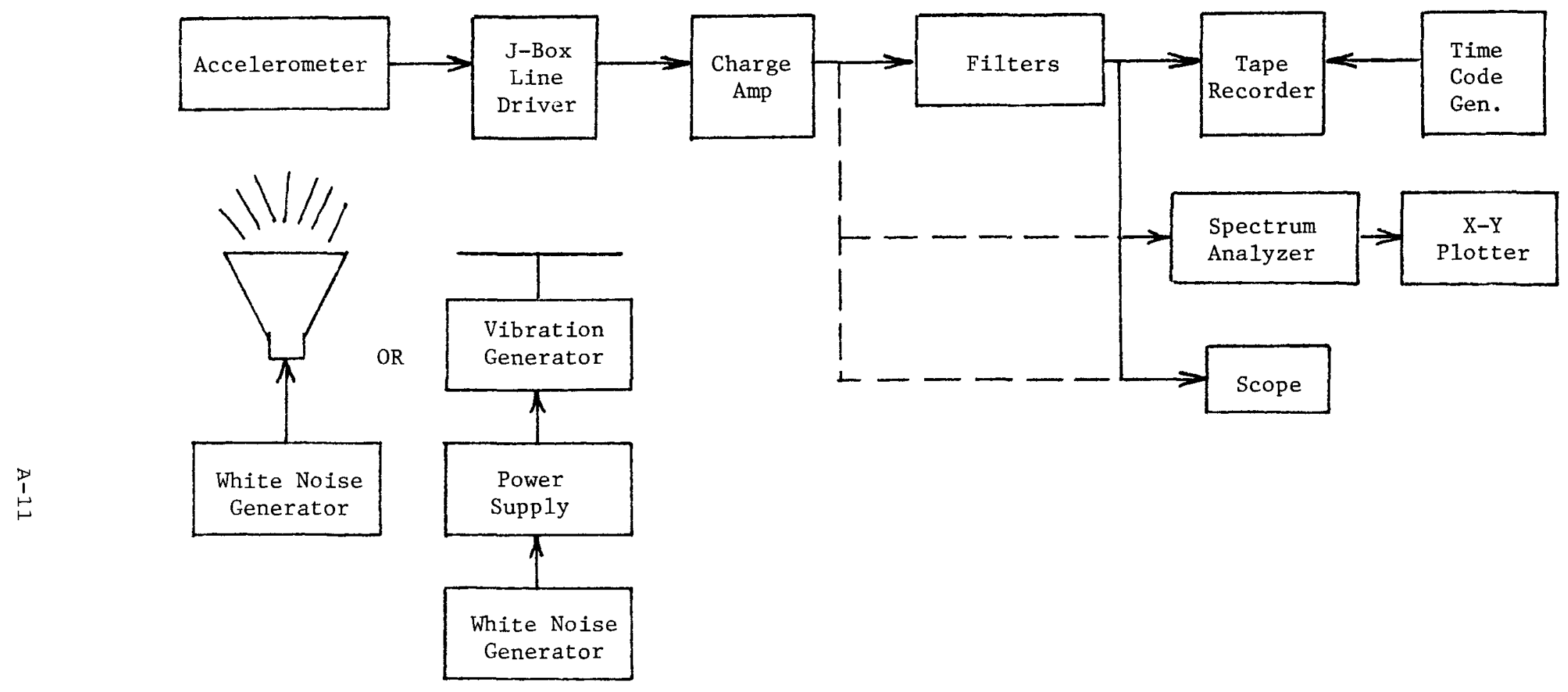


Attachment 3 - Instrument Channel Checkout, Transducer Substitution Method

1. Connect the substitute accelerometer to the signal channel to be tested at the line driver.

2. Mount the accelerometer on the Unholtz-Dickie shaker.

3. Adjust the shaker for the gram weight of the accelerometer and mount to achieve 1 gram on the accelerometer.

4. Adjust the charge amp sensitivity for a DVM reading of $0.707 \mathrm{~V}$ for a 1-gram range setting. Log specified sensitivity of accelerometer and sensitivity adjustment value.

5. Attach the Wavetech Mode1 132 white noise generator to the instrument channel to be tested at the line driver via an Endevco 1000 pf precision capacitor.

6. Input a white noise spectrum into the signal channel and obtain a PSD of the channel response. Adjust gains as necessary.

7. Set the sensitivity adjust to the computed value (D) determined as follows:

$$
\begin{array}{ll}
\text { Columbia specified charge sensitivity } \mathrm{pc} / \mathrm{g} & =\mathrm{A} \\
\text { Charge amp setting from step } 4 & =\mathrm{B} \\
\text { Endevco specified charge sensitivity } \mathrm{pc} / \mathrm{g} & =\mathrm{C} \\
\text { Charge sensitivity setting } & =\mathrm{D} \\
\qquad \mathrm{D}=\mathrm{A}(\mathrm{B} / \mathrm{C}) &
\end{array}
$$

8. Repeat for all instrument channels. 


\section{Attachment 4 - In-Air Resonant Tube Tests}

Tape channe1

\begin{tabular}{|c|c|c|c|c|c|c|}
\hline No. & Row & Tube & & Accel ID & & \\
\hline 1 & 20 & 55 & $\mathrm{x}$ & $\mathrm{Y}_{-}$ & $\mathrm{x}$ & $\mathrm{Y}$ \\
\hline 2 & 105 & 90 & $\mathrm{x}$ & $Y$ & $\mathrm{x}$ & $\mathrm{Y}$ \\
\hline 3 & 69 & 23 & $\mathrm{x}$ & $Y_{-}$ & $\mathrm{x}$ & Y \\
\hline 4 & 132 & 25 & $\mathrm{x}$ & $\mathrm{Y}$ & $\mathrm{x}$ & $\mathrm{Y}$ \\
\hline 5 & 107 & 83 & $\mathrm{x}$ & $Y_{-}$ & $\mathrm{X}$ & $Y$ \\
\hline 6 & 128 & 93 & $\mathrm{x}$ & $Y$ & $\mathrm{X}$ & $Y$ \\
\hline 7 & 87 & 55 & $\mathrm{x}$ & $\mathrm{Y}$ & $\mathrm{x}$ & $Y$ \\
\hline 8 & 75 & 54 & $\mathrm{x}$ & $\mathrm{Y}$ & $\mathrm{x}$ & $Y$ \\
\hline 9 & 121 & 28 & $\mathrm{x}$ & $Y$ & $\mathrm{X}$ & $Y$ \\
\hline 10 & 52 & 30 & $\mathrm{x}$ & $Y_{-}$ & $\mathrm{x}$ & $Y_{-}$ \\
\hline 11 & 33 & 18 & $\mathrm{x}$ & $Y_{-}$ & $\mathrm{X}$ & $Y$ \\
\hline 12 & 119 & 35 & $\mathrm{x}$ & $\mathrm{Y}$ & $\mathrm{X}$ & $Y$ \\
\hline 13 & 100 & 70 & $\mathrm{x}$ & $Y_{-}$ & $x$ & $Y$ \\
\hline 14 & 44 & 14 & $\mathrm{x}$ & $Y$ & $\mathrm{x}$ & $\mathrm{Y}$ \\
\hline 15 & 143 & 20 & $\mathrm{X}$ & $Y$ & $x$ & $Y$ \\
\hline 16 & 79 & 70 & $\mathrm{x}$ & $Y$ & $x$ & Y \\
\hline 17 & 132 & 83 & $\mathrm{x}$ & $Y_{-}$ & $\mathrm{x}$ & $Y_{-}$ \\
\hline 18 & 111 & 3 & $\mathrm{x}$ & Y & $\mathrm{x}$ & $Y$ \\
\hline 19 & 93 & 52 & $\mathrm{x}$ & $Y_{-}$ & $\mathrm{x}$ & $Y$ \\
\hline 20 & 29 & 52 & $\mathrm{x}$ & $Y_{-}$ & $\mathrm{x}$ & $Y$ \\
\hline 21 & 65 & 70 & $x_{-}$ & $Y$ & $\mathrm{X}$ & Y \\
\hline 22 & 55 & 81 & $x$ & $Y$ & $\mathrm{x}$ & Y \\
\hline 23 & 135 & 79 & $\mathrm{x}$ & $Y$ & $\mathrm{X}$ & $\mathrm{Y}$ \\
\hline 24 & 18 & 39 & $\mathrm{x}$ & $Y$ & $\mathrm{X}$ & Y \\
\hline 25 & 72 & 125 & $\mathrm{x}$ & $\mathrm{Y}$ & $x$ & $Y$ \\
\hline 26 & 17 & 39 & $\mathrm{x}$ & $\mathrm{Y}$ & $\mathrm{X}$ & $Y$ \\
\hline 27 & 119 & 3 & $\mathrm{x}$ & $\mathrm{Y}$ & $\mathrm{X}$ & $\mathrm{Y}$ \\
\hline 28 & 21 & 20 & $\mathrm{X}$ & $\mathrm{Y}_{-}$ & $\mathrm{X}$ & $Y$ \\
\hline 29 & 31 & 44 & $\mathrm{x}$ & $\mathrm{Y}$ & $\mathrm{X}$ & $Y$ \\
\hline 30 & 39 & 79 & $\mathrm{X}$ & $\mathrm{Y}$ & $\mathrm{X}$ & $\mathrm{Y}$ \\
\hline
\end{tabular}




\section{Attachment 4 (Cont'd)}

Tape channe 1

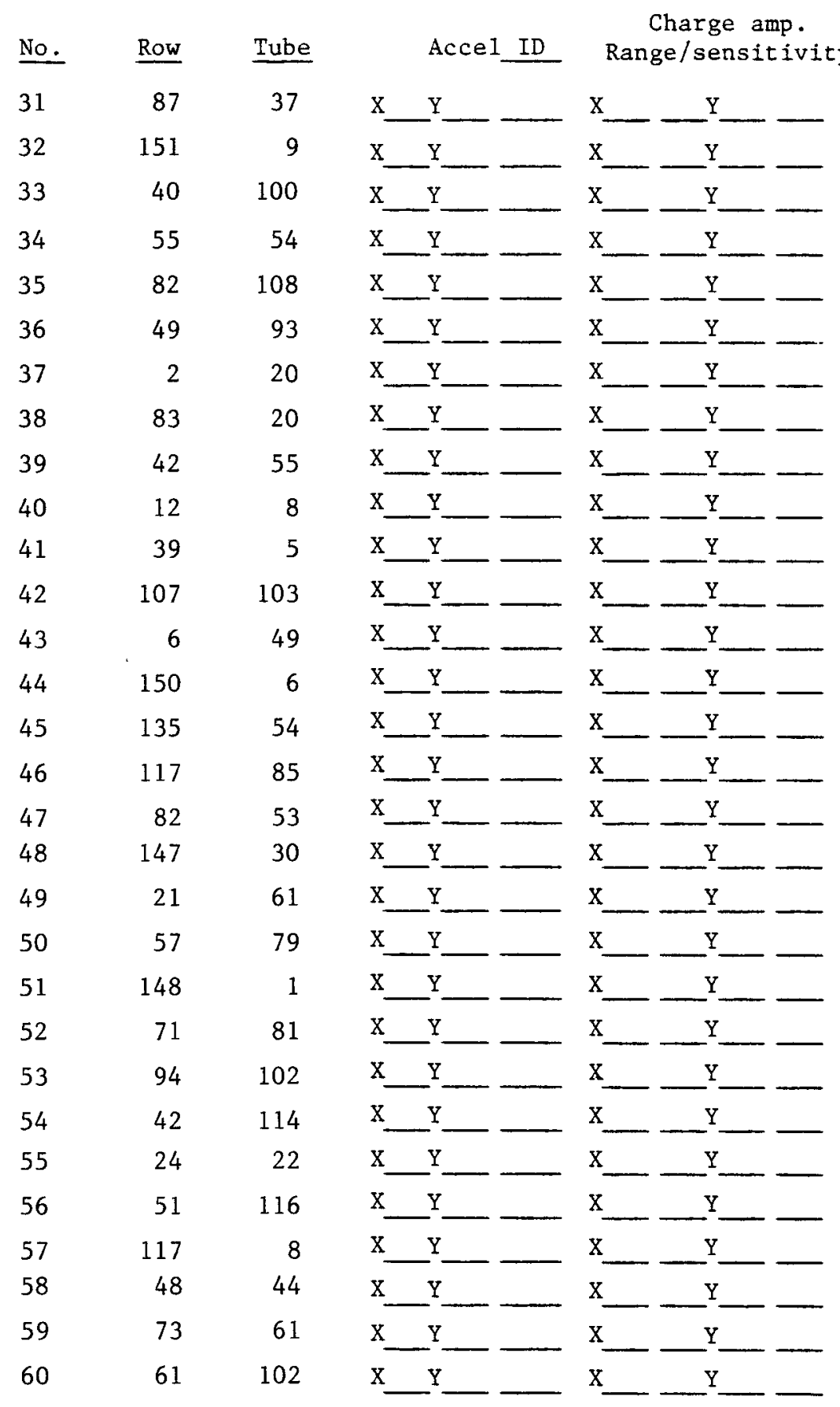




\section{Attachment 4 (Cont'd)}

Tape channe1

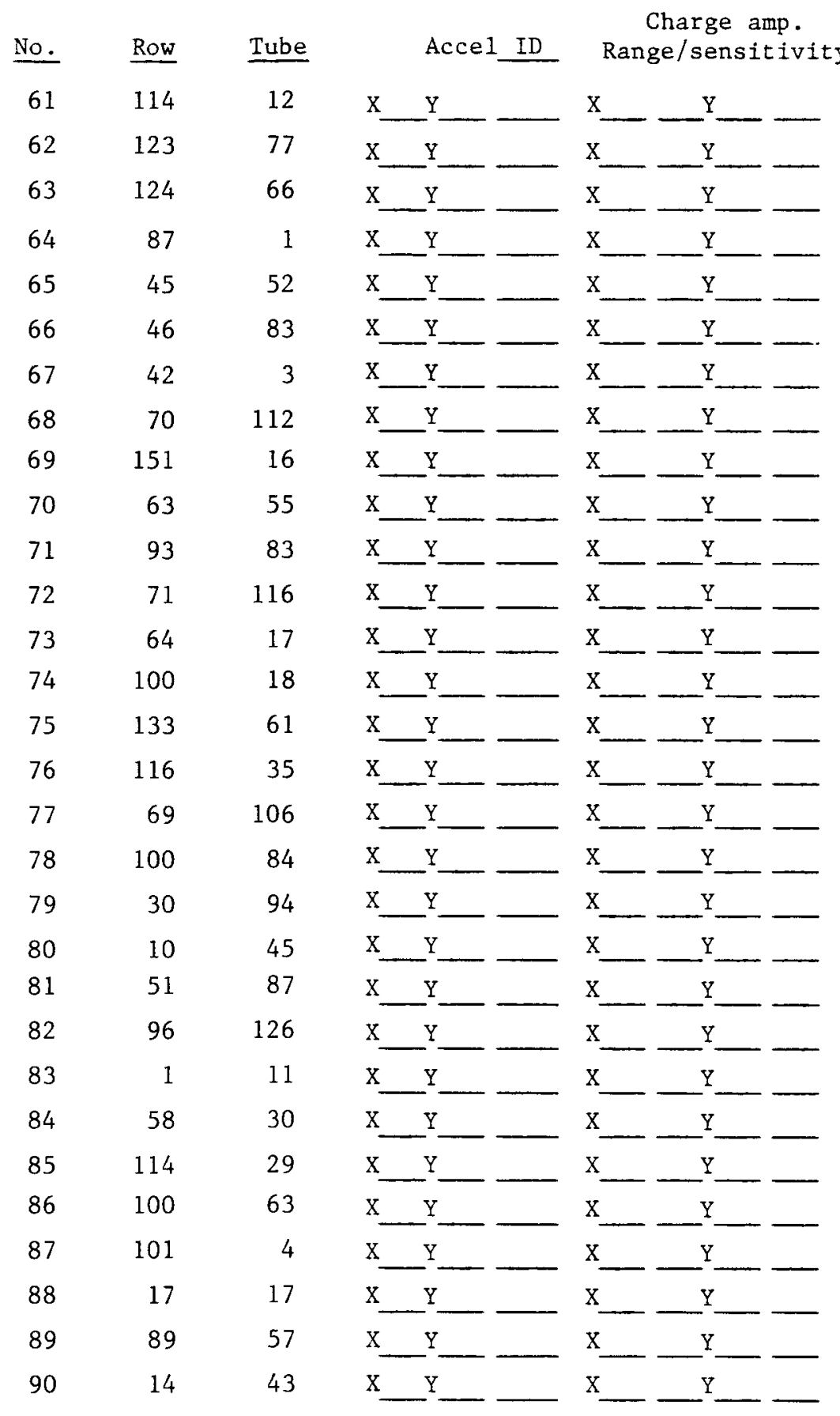


Attachment 4 (Cont'd)

Tape channel

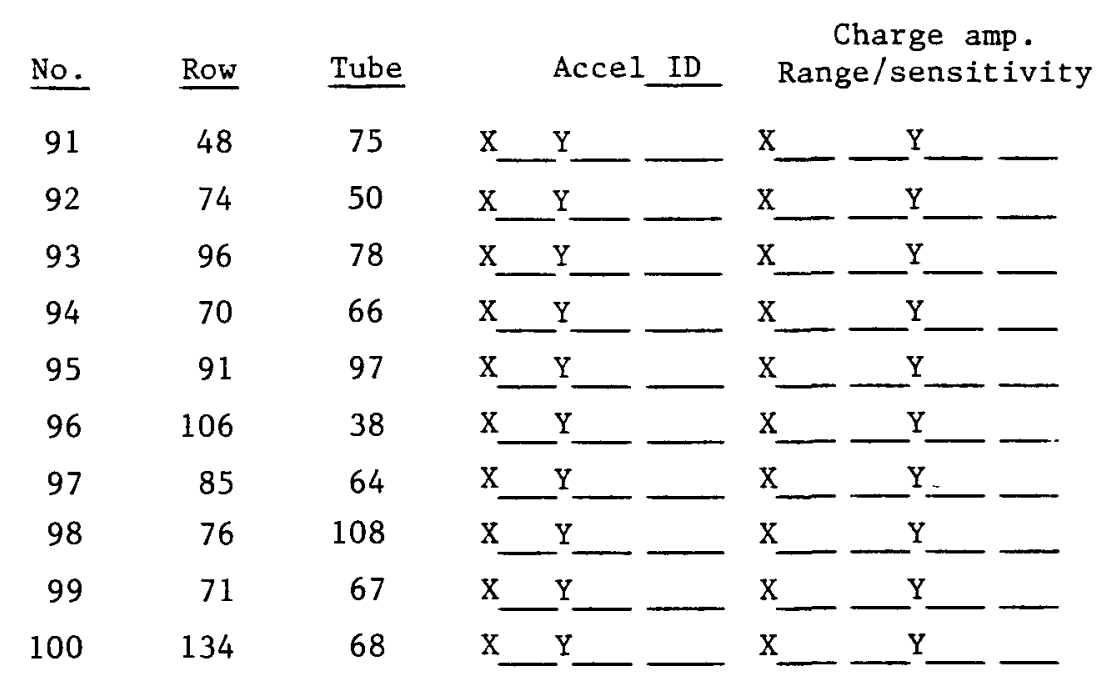




\section{Attachment 5-Ninth/Tenth Span Mode Shape -}

Tube-Tape Matrix

Tape channel

Charge amp.

Range/sens.

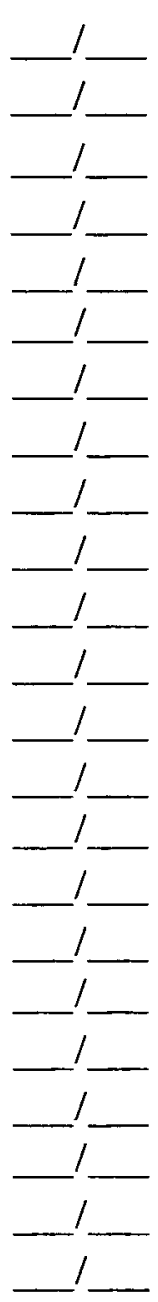

\begin{tabular}{|c|c|c|}
\hline Row & Tube & Ref. Accel \\
\hline 12 & 068 & $\mathrm{X} \quad \mathrm{Y}$ \\
\hline 13 & 069 & $\mathrm{X} \quad \mathrm{Y}$ \\
\hline 14 & 069 & $\mathrm{X} \quad \mathrm{Y}$ \\
\hline 29 & 076 & $\mathrm{X} \quad \mathrm{Y}$ \\
\hline 39 & 114 & $\mathrm{X} \quad \mathrm{Y}$ \\
\hline 40 & 113 & $\mathrm{X} \quad \mathrm{Y}$ \\
\hline 49 & 103 & $\mathrm{X} \quad \mathrm{Y}$ \\
\hline 71 & 019 & $\mathrm{X} \quad \mathrm{Y}$ \\
\hline 73 & 019 & $\mathrm{X} \quad \mathrm{Y}$ \\
\hline 75 & 019 & $\mathrm{X} \quad \mathrm{Y}$ \\
\hline 77 & 001 & $\mathrm{X} \quad \mathrm{Y}$ \\
\hline 77 & 004 & $\mathrm{X} \quad \mathrm{Y}$ \\
\hline 77 & 015 & $\mathrm{X}$ \\
\hline 77 & 021 & $\mathrm{X}$ \\
\hline 77 & 023 & $\mathrm{X}$ \\
\hline 77 & 030 & $\mathrm{X}$ \\
\hline 77 & 035 & $\mathrm{X}$ \\
\hline 77 & 040 & $\mathrm{X}$ \\
\hline 77 & 050 & $\mathrm{X}$ \\
\hline 77 & 008 & $\mathrm{X}$ \\
\hline 77 & 013 & $\mathrm{x}$ \\
\hline 42 & 110 & $\mathrm{X}$ \\
\hline 77 & 019 & $\mathrm{X}$ \\
\hline
\end{tabular}

Movable

accel ID

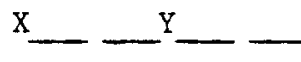

$\mathrm{X}$

$\mathrm{X}-\mathrm{Y}-\mathrm{Y}$

$\mathrm{X}$

$\mathrm{X}$

$\mathrm{X}-\frac{\mathrm{Y}}{\mathrm{Y}}-$

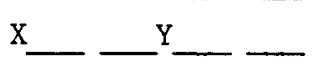

$\mathrm{X}$

$\mathrm{X}-\mathrm{Y}$

$\mathrm{X}--\mathrm{Y}-\mathrm{Y}$

$\mathrm{X}-\mathrm{Y}-$

$\mathrm{X}$

$\mathrm{X}-\mathrm{Y}-$

$\mathrm{X}-\mathrm{Y}-\mathrm{Y}$

$\mathrm{X}$

$\mathrm{X}$

$\mathrm{X} \_\mathrm{Y}$

$\mathrm{X}-\mathrm{Y}$

$\mathrm{X}-\frac{\mathrm{Y}}{\mathrm{X}-\mathrm{Y}-\mathrm{Y}}-$

$\mathrm{X}-\mathrm{Y}$ 


\section{Attachment 6 -Mounting Detail}

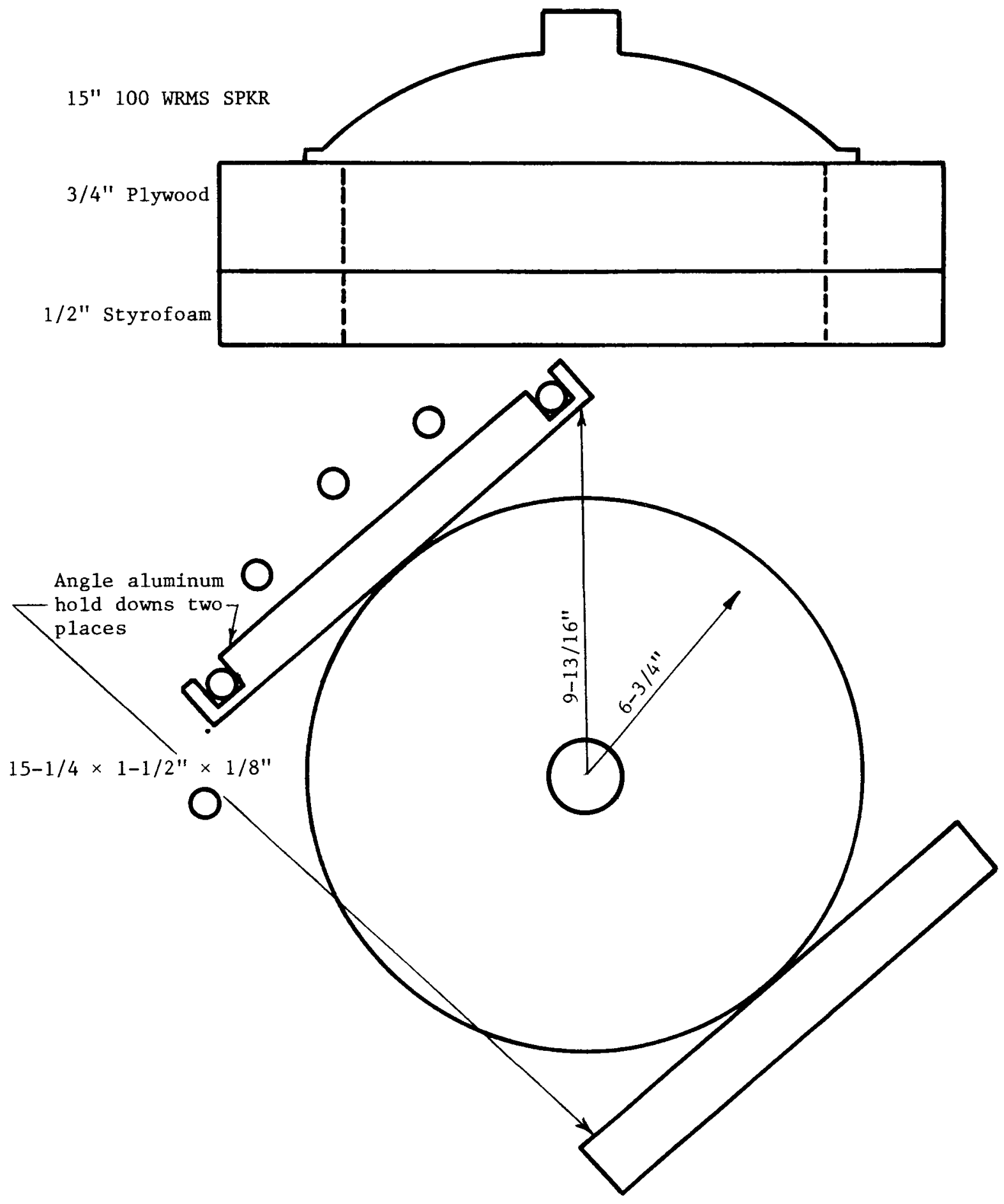




\section{Attachment 6 (Cont'd)}

1. Secondary manway vibration generator stud mount

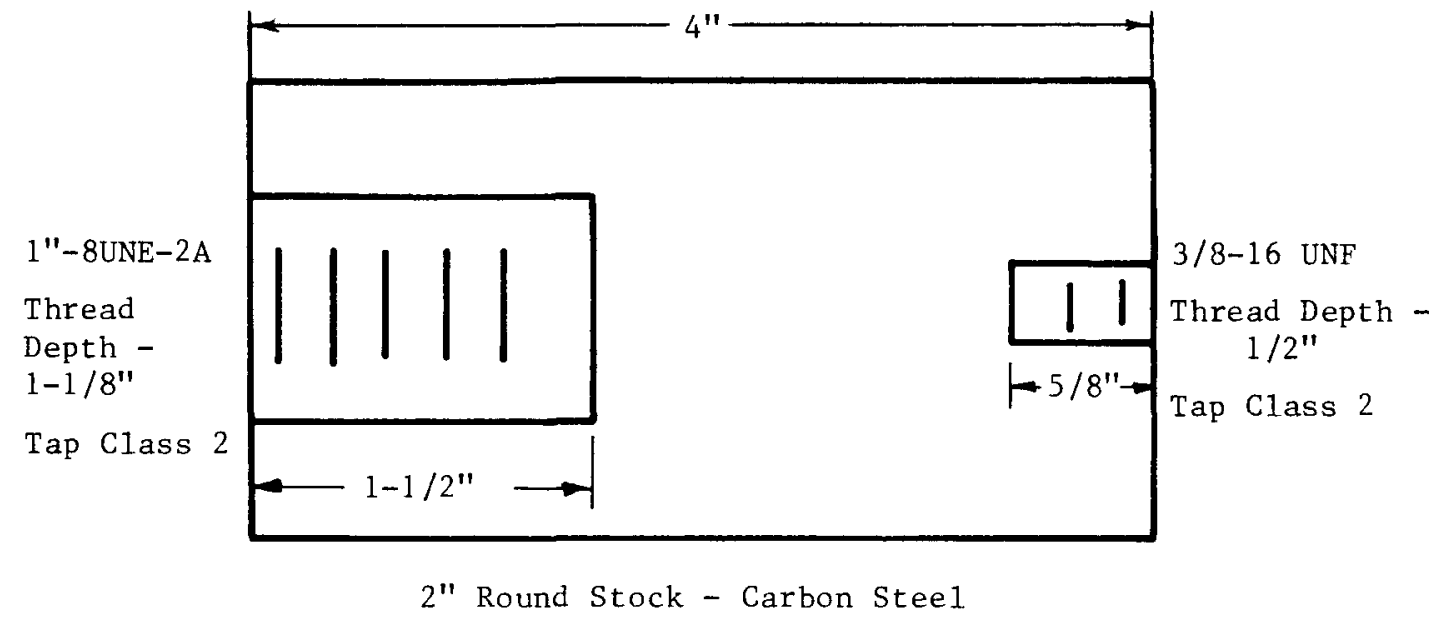

2. Main FW nozzle vibration generator stud mount as above except drill and tap left face for $1-1 / 4^{\prime \prime}-8 \mathrm{UN}-2 \mathrm{~A}$ 


\section{Installation of Lower (Reference)}

Accelerometers

a. Tie a 70-foot length of cord to a plumb bob and lower the plumb bob into the desired tube until it exits the lower tubesheet.

b. Using gray duct tape, tape the leading 6-inch length of 80-1b test stainless steel leader to the accelerometer leads.

c. Tie the cord around the leads and leader and pull a11 three into the bottom tubesheet until 3 feet of signal cable is left at the top.

d. Cut the stainless steel leader, loop through the eye of the accelerometer on the lead end and secure by crimping a metal clasp around the parallel lengths of leader. Trim excess leader to top of clasp.

e. Guide the accelerometer into the tube to the appropriate depth by measuring the insertion of the installation tool, and not the orientation of the axes. Record this information in Table 1 or 2, as appropriate.

f. Connect the signal leads to the line drivers, and connect the line drivers to the TSP cable provided at the lower head area.

2. Installation of Upper (Movable) Accelerometer

a. Loop a stainless steel leader through the eye of the accelerometer on the lead end and secure by crimping a metal clasp around the parallel lengths of leader. Trim excess leader to top of clasp.

b. Guide the accelerometer into the tube with the axes oriented to match the reference accelerometer to the appropriate depth by measuring the insertion of the installation tool. Record this information in Table 1 or 2 , as appropriate.

\section{Position Adjustment}

The position of the movable accelerometer can be adjusted down using the installation tool, noting the tool installation lengths, or up by pulling it up with the leader, noting the leader withdrawal length.

CAUTION: Do NOT attempt to move the accelerometers by pulling on the signal cables. 


\section{Accelerometer Removal}

Accelerometers are to be removed by pulling them from the tubes by the stainless steel leaders.

CAUTION: Do NOT attempt to move the accelerometers

by pulling on the signal cables. 


\section{APPENDIX B}

Test Case

Curve fit function:

$$
\begin{aligned}
y=0.00028+8.0008 x & +1.2388 x^{2} \\
& -18.4759 x^{3}+9.2361 x^{4}
\end{aligned}
$$

Residual sum of squares $=0.00001041$

Coefficient of determination $=0.9999$ 


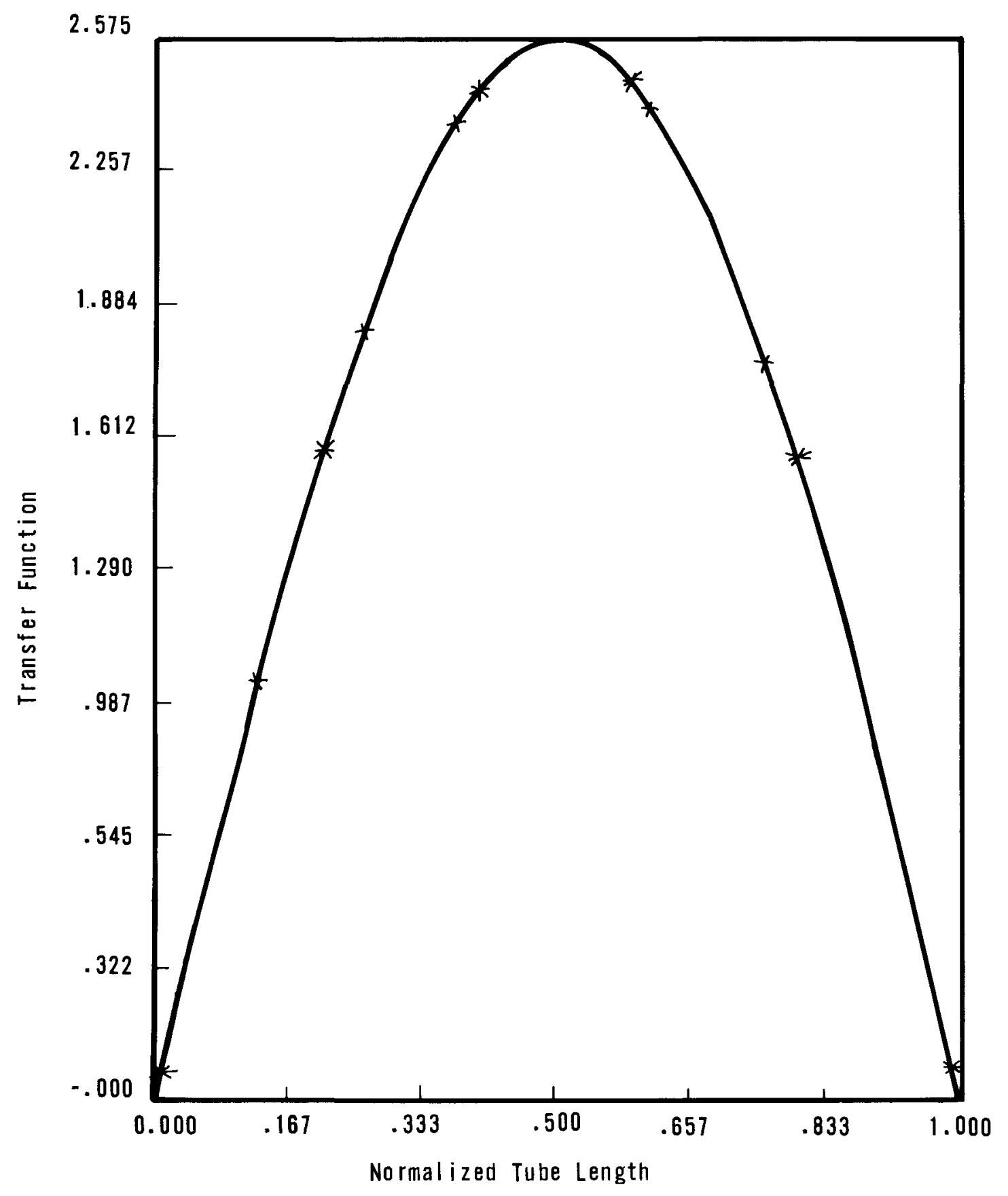

Figure B-1. Curve Fit for Test Case 
APPENDIXES $C, D, \& E$

These appendixes are available only

in microfiche form as volume 2 
- 


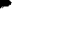




\section{2 \\ $+4$}

4

T.

7.

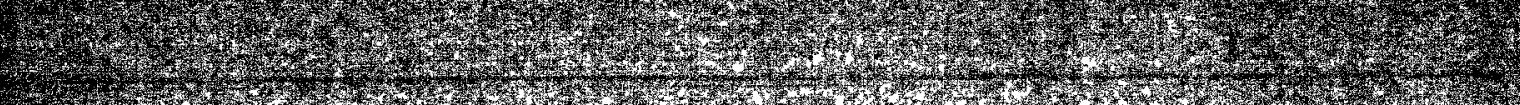

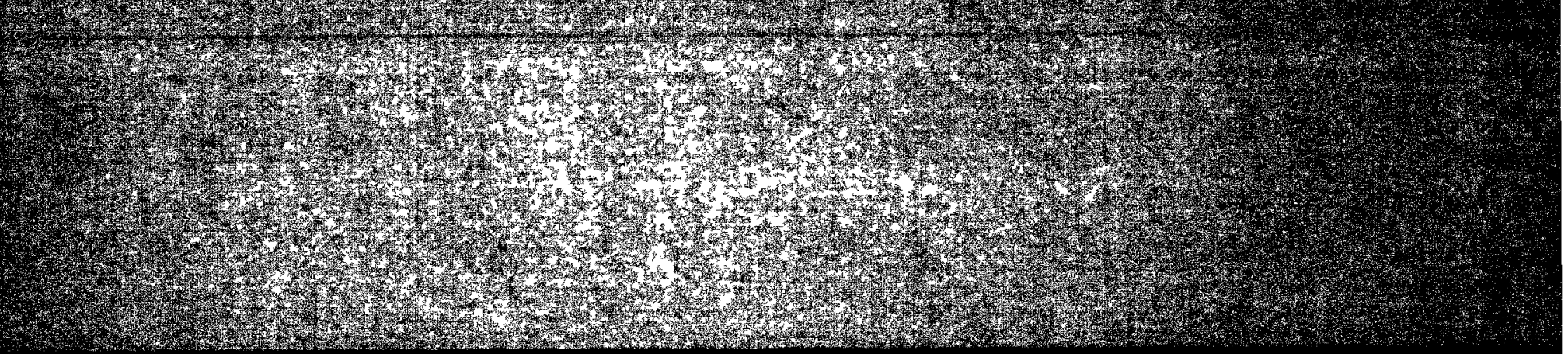
1. 